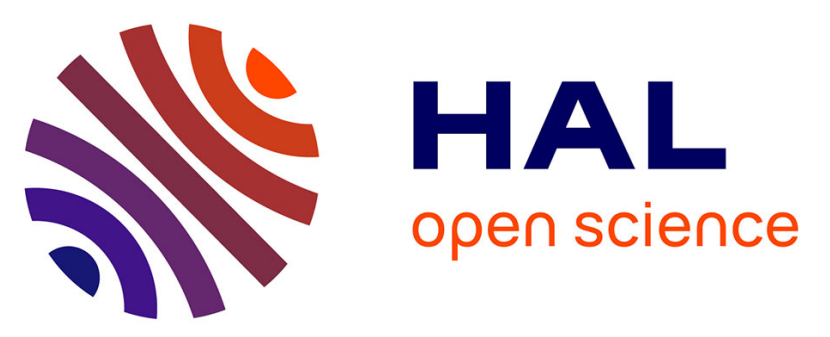

\title{
Sepsis expands a CD39+ plasmablast population that promotes immunosuppression via adenosine-mediated inhibition of macrophage antimicrobial activity
}

\author{
Daniele Carvalho Nascimento, Paula Ramos Viacava, Raphael Gomes
}

Ferreira, Marina Alves Damaceno, Annie Rocío Piñeros, Paulo Henrique Melo, Paula Barbim Donate, Juliana Escher Toller-Kawahisa, Daniel Zoppi, Flávio Protásio Veras, et al.

\section{- To cite this version:}

Daniele Carvalho Nascimento, Paula Ramos Viacava, Raphael Gomes Ferreira, Marina Alves Damaceno, Annie Rocío Piñeros, et al.. Sepsis expands a CD39+ plasmablast population that promotes immunosuppression via adenosine-mediated inhibition of macrophage antimicrobial activity. Immunity, 2021, 54 (9), pp.2024-2041.e8. 10.1016/j.immuni.2021.08.005 . hal-03429634

\author{
HAL Id: hal-03429634 \\ https://hal.science/hal-03429634
}

Submitted on 15 Nov 2021

HAL is a multi-disciplinary open access archive for the deposit and dissemination of scientific research documents, whether they are published or not. The documents may come from teaching and research institutions in France or abroad, or from public or private research centers.
L'archive ouverte pluridisciplinaire HAL, est destinée au dépôt et à la diffusion de documents scientifiques de niveau recherche, publiés ou non, émanant des établissements d'enseignement et de recherche français ou étrangers, des laboratoires publics ou privés. 


\section{Sepsis expands a CD39+ plasmablast population that promotes}

2 immunosuppression via adenosine-mediated inhibition of 3 macrophage antimicrobial activity

5 Daniele Carvalho Nascimento ${ }^{1,2,3}$, Paula Ramos Viacava ${ }^{1,2}$, Raphael Gomes 6 Ferreira ${ }^{1,2}$, Marina Alves Damaceno ${ }^{4}$, Annie Rocío Piñeros ${ }^{1,2}$, Paulo Henrique 7 Melo $^{1,2}$, Paula Barbim Donate ${ }^{1,2}$, Juliana Escher Toller-Kawahisa ${ }^{1,2}$, Daniel 8 Zoppi $^{5}$, Flávio Protásio Veras ${ }^{1,2}$, Raphael Sanches Peres ${ }^{1,2}$, Luísa Menezes9 Silva $^{6}$, Diego Caetité ${ }^{1,2}$, Antonio Edson Rocha Oliveira ${ }^{7}$, Ícaro Maia Santos de 10 Castro $^{7}$, Gilles Kauffenstein ${ }^{8}$, Helder Imoto Nakaya ${ }^{7}$, Marcos Carvalho Borges ${ }^{5}$, 11 Dario Simões Zamboni ${ }^{2,9}$, Denise Morais da Fonseca ${ }^{6}$, Jonas Augusto Rizzato 12 Paschoal $^{4}$, Thiago Mattar Cunha ${ }^{1,2}$, Valerie Quesniaux ${ }^{3,10}$, Joel Linden ${ }^{11}$, 13 Fernando Queíroz Cunha ${ }^{1,2}$, Bernhard Ryffel ${ }^{3,10}$ and José Carlos Alves-Filho ${ }^{1,2}$

\section{Affiliations}

${ }^{1}$ Departments of Pharmacology, Ribeirão Preto Medical School, University of São Paulo,

17 Ribeirão Preto, SP, 14049-900, Brazil;

${ }^{2}$ Center for Research in Inflammatory Diseases, Ribeirão Preto Medical School,

19 University of São Paulo, Ribeirão Preto, SP, 14049-900, Brazil;

$20 \quad{ }^{3}$ CNRS, UMR7355, Orleans, 45071, France;

$21{ }^{4}$ Department of Biomolecular Sciences, School of Pharmaceutical Sciences of Ribeirão

22 Preto, University of São Paulo, Ribeirão Preto, SP, 14049-900, Brazil;

23 5epartment of Internal Medicine, Ribeirão Preto Medical School, University of São 24 Paulo, Ribeirão Preto, SP, 14049-900, Brazil.

$25{ }^{6} \mathrm{ICB}$ - Institute of Biomedical Sciences, University of São Paulo, São Paulo, SP, 0550826 000, Brazil; 
$1 \quad{ }^{7}$ Department of Clinical and Toxicological Analyses, School of Pharmaceutical Sciences,

2 University of São Paulo, São Paulo, SP, 05508-000, Brazil;

3 'UMR INSERM 1260, Regenerative NanoMedicine, University of Strasbourg,

4 Strasbourg, 60026, France;

$5{ }^{9}$ Department of Cell Biology, Ribeirão Preto Medical School, University of São Paulo,

6 Ribeirão Preto, SP, 14049-900, Brazil;

$7{ }^{10}$ Experimental and Molecular Immunology and Neurogenetics, University of Orleans,

8 Orleans, 45071, France;

$9 \quad{ }^{11}$ Division of Nephrology, Center for Immunity, Inflammation and Regenerative Medicine

10 University of Virginia School of Medicine, Charlottesville, VA 22903, USA.

11

12 Corresponding authors

13 Daniele Carvalho Nascimento

14 danielecbn@usp.br

15 José Carlos Alves-Filho

16 jcafilho@usp.br

17

18 Lead contact

19 José Carlos Alves-Filho

20 jcafilho@usp.br

21

22 Keywords: Sepsis, adenosine, immunosuppression, B cells, plasmablast, 23 macrophages. 


\section{Abstract}

2 Sepsis results in elevated adenosine in circulation. Extracellular adenosine triggers

3 immunosuppressive signaling via the $A 2 a$ receptor (A2aR). Sepsis survivors develop

4 persistent immunosuppression with increased risk of recurrent infections. We utilized the

5 cecal ligation and puncture (CLP) model of sepsis and subsequent infection to assess

6 the role of adenosine in post-sepsis immune suppression. A2aR-deficient mice showed

7 improved resistance to post-sepsis infections. Sepsis expanded a subset of CD39hi B

8 cells and elevated extracellular adenosine, which was absent in mice lacking CD39-

9 expressing B cells. Sepsis-surviving B cell-deficient mice were more resistant to

10 secondary infections. Mechanistically, metabolic reprogramming of septic B cells

11 increased production of ATP, which was converted into adenosine by CD39 on

12 plasmablasts. Adenosine signalling via A2aR impaired macrophage bactericidal activity

13 and enhanced interleukin-10 production. Septic patients exhibited expanded CD39hi

14 plasmablasts and adenosine accumulation. Our study reveals CD39hi plasmablasts and

15 adenosine as important drivers of sepsis-induced immunosuppression, with relevance in

16 human disease. 


\section{INTRODUCTION}

2 Sepsis is a systemic inflammation triggered by pathogens that leads to organ

3 dysfunction (Singer et al., 2016). Although advances in supportive care have

4 reduced sepsis mortality over the last decades (Prescott and Angus, 2018),

5 patients who survive severe sepsis have a high number of re-hospitalizations and

6 increased mortality mainly due to recurrent infections (Otto et al., 2011; Wang et

7 al., 2014). Compelling clinical and experimental studies indicate that sepsis may

8 cause an immunosuppressive state that accounts for increased susceptibility to

9 secondary, mostly opportunistic, infections (Benjamim et al., 2003; Boomer et al.,

10 2011; Nascimento et al., 2017; Otto et al., 2011). Potential mechanisms for

11 sepsis-induced immunosuppression include immune cell apoptosis, expansion of

12 the regulatory $\mathrm{T}$ (Treg) cell population, and impaired microbial killing by

13 macrophages (M $\varphi s$ ) (Venet and Monneret, 2018). However, the mechanisms

14 underlying the persistent dysregulation of the host immune response in sepsis

15 survivors are not entirely understood.

16 Extracellular adenosine is a signaling molecule that modulates several

17 immunological processes via specific receptors expressed on immune cells

18 (Hasko et al., 2008). Adenosine binds four different receptors: adenosine

19 receptor 1 (A1R), A2aR, A2bR, and A3R (Fredholm et al., 2001). The signaling

20 mediated by $\mathrm{A} 2 \mathrm{aR}$ augments the production of anti-inflammatory cytokines,

21 inhibits $T$ cell proliferation, suppresses microbial killing by neutrophils and $M \varphi s$,

22 and enhances differentiation of M2 M

23 Cronstein, 2013). 
1 A major source of extracellular adenosine is ATP hydrolysis by

2 ectonucleotidases, such as CD39 and CD73 (Allard et al., 2017). CD39

3 (ectonucleoside triphosphate diphosphohydrolase-1, ENTPD1) catalyzes the

4 hydrolysis of extracellular ATP and ADP to AMP, while CD73 (ecto-5'

5 nucleotidase, E5NT) converts AMP into adenosine (Colgan et al., 2006; Dwyer

6 et al., 2007). During the acute phase of sepsis, patients show elevated adenosine

7 levels in circulation (Jabs et al., 1998; Martin et al., 2000; Ramakers et al., 2011).

8 We, therefore, hypothesized that increased extracellular adenosine might

9 contribute to the development of immune suppression in sepsis survivors via

10 activation of A2aR in immune cells.

11 Here, we showed that sepsis induced the expansion of splenic CD39hi CD138 hi 12 plasmablasts, which generated increased extracellular adenosine in sepsis

13 survivors. Adenosine derived from $\mathrm{CD} 39^{\text {hi }} \mathrm{CD} 138^{\text {hi }}$ plasmablasts promoted

14 suppression of the immune response by impairing the microbicidal activity of

15 macrophages via $A 2 a R$ activation, rendering sepsis-surviving mice highly

16 susceptible to secondary infections. Myeloid-specific deletion of A2aR improved

17 the microbial resistance of sepsis-surviving mice. We found that septic patients

18 also had an increased frequency of immunosuppressive CD39hi plasmablasts

19 and adenosine accumulation in the blood. Our data, therefore, suggest that 20 adenosine can be a potential therapeutic target for persistent 21 immunosuppression in sepsis survivors. 


\section{RESULTS}

\section{Adenosine via A2aR mediates sepsis-induced immunosuppression}

3 To investigate whether adenosine contributes to the development of

4 immunosuppression after sepsis, we utilized cecal ligation and puncture (CLP;

$5 \quad 100 \%$ lethality), a clinically relevant sepsis model (Nascimento et al., 2010;

6 Rittirsch et al., 2009). Following CLP, mice received antibiotic treatment

7 (ertapenem), which increased survival (60\%; Figures $1 \mathrm{~A}$ and $1 \mathrm{~B})$. Mice that

8 survived were then challenged at day 15 post-CLP with an intranasal (i.n.) sub-

9 lethal dose of one of two opportunistic human pathogens, L. pneumophila or $A$.

10 fumigatus, to examine host susceptibility to secondary infections (Figure 1A). As

11 previously described (Nascimento et al., 2017), sepsis-surviving mice showed

12 impaired microbial clearance and high susceptibility to both infections (100\% and

$1380 \%$ lethality, respectively), while all naive or sham-operated immune-competent

14 mice survived until the end of the study period (Figures $1 \mathrm{C}-1 \mathrm{~F}$ and Figure S1A).

15 The high susceptibility of sepsis-surviving mice to challenge infection with $L$.

16 pneumophila persisted for at least 75 days post-CLP (Figure 1C). Mice that

17 survived moderate CLP model with or without antibiotics (70\% and $20 \%$ lethality,

18 respectively) were equally susceptible to the challenge infection with $L$.

19 pneumophila (Figures S1B and S1C). We then measured adenosine

20 concentration in the plasma at different time points after sepsis induction (Figure

21 1G). Circulating adenosine increased in sepsis-surviving mice by day 15, which

22 peaked around day 45 and remained elevated above naïve and sham-operated

23 mice out to day 75 (Figures $1 \mathrm{H}$ and $1 \mathrm{I}$, Figures S1D and S1E and Figure S2I). 
1 To investigate whether the A2aR contributes to immunosuppression, we treated

2 CLP mice with A2aR antagonist (A2aRi; 8-3-chlorostyryl-caffeine) (Jacobson et

3 al., 1993) and challenged sepsis-surviving mice with $A$. fumigatus or $L$.

4 pneumophila 15 days post-CLP (Figure 1J). A2aR blockade enhanced host

5 resistance against both infections (Figure $1 \mathrm{~K}$ ) and reduced microbial loads in the

6 lungs and spleen of sepsis-surviving mice (Figure 1L). Sepsis-surviving A2aR-

7 deficient $\left(\right.$ Adora2a $\left.^{-/}\right)$mice also showed lower L. pneumophila counts in the lung

8 and spleen than BALB/c WT mice (Figure 1M). The inhibition or deficiency of

9 A2aR did not alter the survival of antibiotic-treated CLP mice (Figures S2A-S2C).

10 Thus, adenosine signaling via the A2aR is required for the development of sepsis-

11 induced immunosuppression.

\section{Adenosine accumulation in sepsis-surviving mice requires CD39 activity}

14 Because the hydrolysis of extracellular ATP by CD39 is considered the primary source of extracellular adenosine (Robson et al., 2006), we next asked whether CD39 contributes to post-sepsis immunosuppression. Flow cytometry analysis

17 revealed increased CD39 expression in spleen cells from sepsis-surviving mice 15 days post-CLP (Figure 2A). We then incubated spleen cells with ATP and measured inorganic phosphate $(\mathrm{Pi})$ released in the cell supernatants to analyze ecto-ATPase activity. Spleen cells from sepsis-surviving mice showed elevated ecto-ATPase activity 15 days post-CLP compared to naive mice (Figure 2B). This was reduced by pre-incubation with CD39 inhibitor, ARL 67156 (CD39i)

23 (Lévesque et al., 2007). These data suggest that CD39 activity is important for the hydrolysis of ATP by splenic cells from CLP mice. 
1 To investigate whether CD39 is required for the increased circulating adenosine,

2 we induced CLP in CD39-deficient (Entpd1-/) mice or treated C57BL/6 WT mice

3 with CD39i (Figure 2C). Both approaches abolished plasma adenosine 4 accumulation in sepsis-surviving mice (Figures 2D-2F). Moreover, CD39 5 inhibition improved survival rates of sepsis-surviving mice challenged with $A$.

6 fumigatus or L. pneumophila 15 days after CLP (Figure 2G). L. pneumophila 7 counts were reduced in the lungs and spleen of mice treated with CD39i 8 compared to vehicle-treated mice (Figure 2H). Similarly, sepsis-surviving Entpd1-

9 /- mice showed lower fungal burdens in the lungs and a higher survival rate to $A$.

10 fumigatus infection than WT control mice (Figures 2I and 2J). Loss of CD39 did 11 not alter the survival of antibiotic-treated CLP mice (Figures S2D and S2E).

12 These results indicate that CD39 is critical for the production of extracellular 13 adenosine and sepsis-induced immunosuppression development.

\section{Sepsis promotes the expansion of a CD39-expressing B cell population}

CD39 is expressed on many immune cell types (Antonioli et al., 2013; Dwyer et al., 2007). To gain an unbiased perspective on the CD39 expression pattern in

18 immune cells from sepsis-surviving mice, we performed high-dimensional flow cytometric analyses of the splenic CD39+ ${ }^{+}$cell populations of naïve and sepsissurviving mice. We used the t-distributed stochastic neighbor embedding (t-SNE)

21 algorithm to perform an unsupervised analysis of the entire flow cytometry 22 dataset (10 samples) generated from naïve and sepsis-surviving mice. 23 Representative t-SNE maps color-coded according to cluster annotation for 24 immune cell populations. Expression intensity revealed that most immune cell populations express CD39 in both naive and sepsis-surviving mice 15 days after 
1 CLP (Figures 3A and 3B and Figures S3A and S3B). However, the frequency of

$2 \mathrm{CD} 9^{+} \mathrm{B}$ cells and the levels of CD39 expression in B cells were particularly

3 increased in sepsis-surviving mice compared to other immune cell populations

4 and B cells from naïve mice (Figure $3 \mathrm{C}$ and Figure S3B). Moreover, a small

5 population of CD39hi B cells was enriched in the spleens of sepsis survivors

6 (Figures 3B and $3 \mathrm{C}$ and Figure S3B). CD39 expression was also increased in B

7 cells from the blood but not from peripheral lymph nodes (LNs) of sepsis-surviving

8 mice (Figures S3C and S3D). Compared with naïve mice, an increased

9 proportion of $\mathrm{CD} 39^{\text {hi }}$ splenic B cells from sepsis-surviving mice co-expressed the

10 proliferation marker Ki67 (Gerdes et al., 1984), suggesting that sepsis leads to

11 an expansion of a CD39 ${ }^{\text {hi }} B$ cell population (Figure 3D). Sham and naive mice \pm

12 antibiotics showed a lower frequency of splenic CD39+ B cells than sepsis-

13 surviving mice 15 days after CLP (Figure S1F).

To characterize B cell subsets expressing CD39, a separate high-dimensional

16 flow cytometric analysis was performed. We enriched $\mathrm{CD} 45^{+} \mathrm{CD} 19^{+} \mathrm{B}$ cell 17 populations from spleens by negatively selecting against the $T$ and Treg cell markers CD3 and Foxp3. We then identified various CD19+ $B$ cell subsets based

19 on traditional flow cytometry gating strategies, as described (Culton et al., 2006;

20 Tung et al., 2006): pre-B (CD138- $\left.\lg M^{-} \lg D^{-}\right)$, immature B (CD138- $\left.\lg M^{+} \lg D^{-}\right)$, early$21{ }^{\left(C^{2} 138^{-} \lg M^{+} \lg D^{+}\right)}$and late-mature $B\left(C^{-} D 138^{-} \lg M^{-} \lg D^{+}\right)$and plasmablast 22 (CD138 hi) cells (Figure S3E). Representative t-SNE maps color-coded according 23 to cluster annotation for distinct $\mathrm{CD}^{2} 9^{+} \mathrm{B}$ cell subsets showed that CD39 is expressed in most splenic B cell populations in both naive and sepsis-surviving mice 15 days after CLP (Figure 3E). However, t-SNE heatmaps revealed that a 
1 differentiated group of cells corresponding to CD138 ${ }^{\text {hi }}$ plasmablasts (orange)

2 showed the highest CD39 expression in sepsis-surviving mice (Figures $3 \mathrm{~F}$ and

$33 G)$. To extend the analysis of CD39 expression on B cell subsets in sepsis-

4 surviving mice, we performed a time-course experiment to profile CD39 5 expression on $\mathrm{B} 1 \mathrm{a}\left(\mathrm{CD} 138^{-} \mathrm{CD}^{+} \mathrm{CD}^{-} 3^{-}\right), \mathrm{B} 1 \mathrm{~b}\left(\mathrm{CD} 138^{-} \mathrm{CD} 5^{-} \mathrm{CD} 23^{-}\right)$, and $\mathrm{B} 2$ 6 (CD138 $\left.^{-} \mathrm{CD}^{-} \mathrm{CD}^{-} 3^{+}\right)$and plasmablast $\left(\mathrm{CD} 138^{\mathrm{hi}}\right)$ cells in the spleen of mice after 7 CLP induction (Figure $3 \mathrm{H}$ ). We confirmed that plasmablasts expressed higher 8 levels of CD39 than other B cell subsets, including B1a, B1b, and B2 cells (Figure

9 3I). Besides, B1a and B1b cells from sepsis-surviving mice had increased 10 expression and frequency of CD39, while these parameters were not altered in 11 B2 cells (Figures 3I-3K). The frequency and the absolute number of $12 \mathrm{CD}_{39}{ }^{+} \mathrm{CD} 138^{\text {hi }} \mathrm{B}$ cells increased in sepsis-surviving mice, peaking on day 7 and returning to baseline levels within 75 days after CLP, indicating that sepsis leads

14 to the expansion of $\mathrm{CD} 39^{+} \mathrm{CD} 138^{\text {hi }} \mathrm{B}$ cells (Figures $3 \mathrm{~J}-3 \mathrm{M}$ ). In support of this, 15 the frequency and number of $K i 67^{+} \mathrm{CD} 39^{+} \mathrm{CD} 138^{\text {hi }} \mathrm{B}$ cells were increased in 16 sepsis-surviving mice (Figures $3 \mathrm{~J}$ and $3 \mathrm{~N}-3 \mathrm{P}$ ). Finally, to address which splenic

17 B cell compartment CD39 ${ }^{\text {hi }} \mathrm{B}$ cells reside, we performed flow cytometry analysis of splenic cells from sepsis-surviving mice on day 7 after CLP, including additional surface markers to characterize marginal zone $(M Z)\left(B 220^{+} \lg M^{+} C D 211^{\text {hi }} C D 23^{l o}\right)$,

20 follicular (FO) $\left(B 220^{+} \operatorname{lgM}{ }^{+} C D 21^{\text {int }} C D 23^{\text {hi }}\right)$, and immature transitional $T 1$ B cells 21 (B220 $\left.^{+} \operatorname{lgM}^{+} \mathrm{CD} 21^{-} \mathrm{CD}^{-} 3^{-}\right)$(Figure S4A). CD39 $9^{\text {hi }} \mathrm{B}$ cells were characterized in 22 immature transitional T1 cells, co-expressing CD138 ${ }^{\text {hi }}$ (Figures S4B and S4C).

23 Thus, sepsis induces the expansion of a CD39 ${ }^{\text {hi }} \mathrm{CD} 138^{\text {hi }}$ plasmablast population. 
1 Our results led us to ask whether B cells contribute to extracellular adenosine

2 production and, consequently, immunosuppression after sepsis. CD19+ $B$ cells

3 sorted from the spleens of sepsis-surviving mice at day 15 post-CLP had

4 increased mRNA levels of Entpd1 (encoding CD39) (Figure 4A). We then

5 assessed ATPase activity and the ability of B cells to generate adenosine through

6 ATP hydrolysis. Upon addition of exogenous ATP, B cells from sepsis-surviving

7 mice showed higher ecto-ATPase activity and produced more adenosine than

8 naive $B$ cells, which was abolished by CD39i (Figure 4B and 4C). Next, we

9 measured plasma adenosine concentrations in Rag $1 \%$ mice, which lack mature

10 T- and B-lymphocytes. Sepsis-surviving Rag 1/ mice showed lower plasma

11 adenosine concentration than WT mice at 15 days post-CLP. Adoptive transfer

12 of naive $\mathrm{CD}_{19}{ }^{+} \mathrm{B}$ cells into Rag1/-recipient mice before CLP induction increased

13 the systemic concentration of adenosine to levels comparable to those observed

14 in septic WT mice (Figures 4D-4F and Figure S2K). Nearly all transferred CD138 ${ }^{\text {hi }}$

15 B cells expressed $\mathrm{CD} 39$, and the $\mathrm{Ki} 67^{+}$proportion was comparable between $\mathrm{B}$

16 cell-recipient Rag $1^{-1-}$ and WT mice. The absolute number of CD39+ $\mathrm{B}$ cells in

17 sepsis-surviving Rag ${ }^{-/}$mice transferred with B cells was lower than WT mice

18 but significantly higher compared to naive WT mice (Figure 4G). Consistently,

19 spleen cells from $\mu \mathrm{MT}^{-/}$mice, which lack mature peripheral B cells, showed low

20 ecto-ATPase activity, and mice failed to raise plasma concentration of adenosine

2115 days after CLP (Figures $4 \mathrm{H}-4 \mathrm{~J}$ and Figure S2J). Sepsis-surviving $\mu \mathrm{MT}^{-/-}$mice

22 were more resistant to $L$. pneumophila infection at day 15 post-CLP, showing

23 higher survival rate and lower bacterial loads in the lungs and spleen than WT

24 mice (Figures $4 \mathrm{~K}$ and $4 \mathrm{~L}$ ). There was no difference in CLP survival between

$25 \operatorname{Rag}^{1-}, \mathrm{MMT}^{-/}$, and WT mice under antibiotic treatment (Figures S2F and S2G). 
2 We then investigated whether the absence of CD39 in B cells would reduce

3 adenosine accumulation in sepsis-surviving mice. To this end, we generated 4 mixed bone marrow (BM) chimeras whereby irradiated WT mice were 5 reconstituted with a mixture of $80 \% \mu \mathrm{MT}^{-/-} \mathrm{BM}$ cells and either $20 \% \mathrm{WT}$ (WT $6 \mu \mathrm{MT}$-chimera) or $20 \%$ Entpd1\% (Entpd1\% $\mu \mathrm{MT}$-chimera) BM cells (Figure 4M).

7 Reconstitution was assessed eight weeks after adoptive transfer (Figures S4D 8 and S4E). With this experimental approach, reconstituted Entpd $1^{-/} \mu \mathrm{MT}$-chimeric

9 mice harbored Entpd1/- B cells in an environment of mostly WT cells. Splenic B 10 cells from WT $\mu \mathrm{MT}$-chimeras showed increased expression of CD39 after CLP 11 compared to naïve mice. In contrast, CD39 expression was reduced in B cells 12 from Entpd1 ${ }^{--} \mu \mathrm{MT}$-chimeric mice from both naïve and CLP groups (Figure 4N). 13 Spleen cells from Entpd1 $1-\mu \mathrm{MT}$-chimeric mice showed low ecto-ATPase activity, and mice failed to increase blood adenosine concentration 15 days after CLP (Figures $4 \mathrm{O}$ and 4P and Figure S2L). Since M $\varphi$ s from sepsis-surviving mice have impaired bactericidal ability (Nascimento et al., 2017), we asked whether the lack of CD39 on B cells would prevent the reduction of bactericidal ability. To this end, peritoneal M $M$ s isolated from sepsis-surviving WT and Entpd1\% $\mu \mathrm{MT}$-chimeric mice were cultured and infected with L. pneumophila, and the number of viable intracellular bacteria was assessed (Figure 4Q). The impaired bactericidal activity 21 found in M $\varphi$ s from WT $\mu \mathrm{MT}$-chimeric mice was not observed in M $\varphi s$ from Entpd1$22{ }^{/} \mu \mathrm{MT}$-chimeric mice (Figure 4R). Finally, we investigated whether septic B cells would directly affect host resistance to infection by transferring sorted CD19 ${ }^{+} \mathrm{B}$ cells from naive or sepsis-surviving mice 15 days post-CLP into naive WT mice. Seven days later, we challenged mice with L. pneumophila i.n. (Figure S5A). Mice 
1 receiving septic $B$ cells showed higher bacteria burdens in the lung than those

2 receiving naive $B$ cells or no $B$ cells, suggesting that septic $B$ cells suppress

3 infection control (Figure S5B). Altogether, our data suggest that CD39+ B cells 4 play a central role in producing adenosine and suppressing the immune response 5 in sepsis survivors.

7 B cell-derived adenosine impairs microbial killing in $M \varphi s$ in vitro

8 To investigate in vitro how septic B cells suppress immune responses to infection,

9 peritoneal M $\varphi$ s from naive mice were infected with $L$. pneumophila and co-

10 cultured with B cells isolated from naive or sepsis-surviving mice for $48 \mathrm{~h}$ (Figure

$115 A$ ). Naive B cells did not affect the ability of $M \varphi s$ to restrict bacterial replication.

12 However, M $\varphi s$ co-cultured with septic B cells contained significantly more

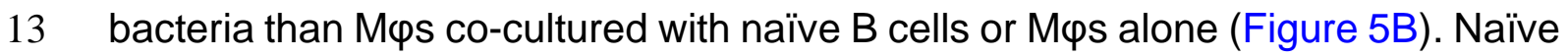

14 or septic B cells did not harbor any intracellular bacteria after $48 \mathrm{~h}$ of culture.

16 The immunomodulatory effects of adenosine include enhanced IL-10 production

17 (Haskó and Pacher, 2012). IL-10 can compromise host defence by directly 18 inhibiting microbial killing by M $\varphi s$ (Couper et al., 2008). IL-10 plays a critical role 19 in the sepsis-induced impairment of lung host defence to secondary infections 20 (Nascimento et al., 2017; Steinhauser et al., 1999). IL-10 production by L. 21 pneumophila-infected M $\varphi$ s was enhanced after $48 \mathrm{~h}$ of co-culture with septic B 22 cells, but not naïve B cells (Figure 5C). Naïve or septic B cells alone released 23 minor levels of IL-10 in response to L. pneumophila infection (Figure 5C). I/10 -

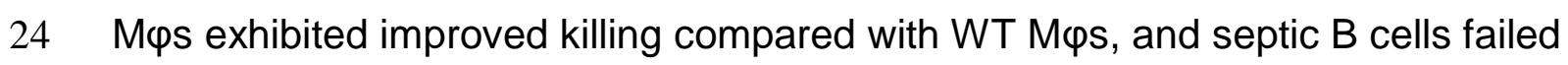


1 to suppress bacterial killing in $/ 110^{-/} \mathrm{M} \varphi$ s (Figure 5D). Thus, IL-10 produced by

2 M $\varphi s$ is critical for the suppressive effect of septic B cells.

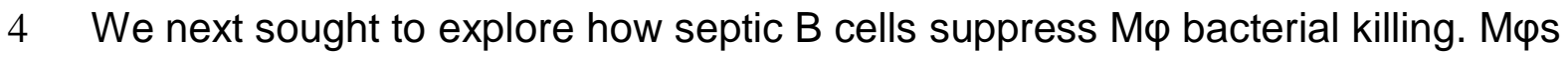
5 treated with CD39i and co-cultured with septic B cells showed enhanced 6 restriction of L. pneumophila replication, similar to levels observed with M $\varphi s$ co7 cultured with naïve B cells or $M \varphi s$ alone (Figure $5 \mathrm{E}$ ). In contrast, the addition of apyrase, a soluble ATPase, in the culture, impaired the restriction of bacterial replication by M $\varphi s$ co-cultured with septic $B$ cells and also with naïve $B$ cells, to a lesser extent (Figure 5E). Supplementation of cultures with ATPyS, a nonhydrolyzable ATP analog, did not affect bacterial killing by $M \varphi s$ alone or in co12 culture with B cells. Conversely, adenosine deaminase (ADA), an adenosinedegrading enzyme, abrogated the suppressive effect of septic B cells on $M \varphi$ bacterial killing (Figure $5 \mathrm{E}$ ). Collectively, these data suggest that the hydrolysis of ATP into adenosine is required for the suppression of $M \varphi$ bacterial killing by septic $B$ cells.

18 Next, Entpd1\% M $\varphi$ s or B cells were co-cultured to examine the relative contribution of CD39 on these cells to suppress microbial killing. Entpd11 M co-cultured with septic WT B cells showed bacterial viability similar to that 21 observed with WT M $\varphi$ s (Figure S5C). In contrast, reduced bacterial viability was seen with CD39 deficiency in septic B cells alone or in both M $M$ s, suggesting restored bacterial killing (Figure 5F and Figure S5C). The addition of apyrase impaired bacterial killing in M $\varphi s$ co-cultured with Entpd1\% septic B cells (Figure 
1 suppressed bacterial killing by M $\varphi$ s, while CD39- septic $B$ cells showed a weak

2 suppressive effect (Figure $5 G$ ). Thus, CD39-expressing septic B cells suppress

$3 \mathrm{M} \varphi$ bacterial killing through adenosine production.

4

5 Next, we investigated the effect of adenosine on $M \varphi$ microbial killing. A2aRi

6 treatment improved bacterial killing, especially in co-culture with septic B cells

7 (Figure S5D). However, A2bR blockade (A2bRi) did not affect the bactericidal

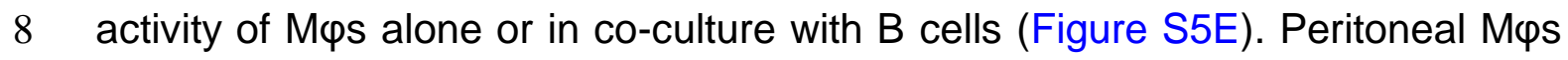

9 from mice lacking A2aR in myeloid cells (Adora2a ${ }^{\triangle L y z 2}$ ) limited intracellular

10 bacterial infection more efficiently than WT $\left(\right.$ Adora2a $\left.^{\mathrm{f} / \mathrm{f}}\right) \mathrm{M} \varphi \mathrm{s}$. Moreover, septic B

11 cells failed to suppress bacterial killing by Adora2a $a^{\Delta L y z 2} \mathrm{M} \varphi s$ (Figure $5 \mathrm{H}$ ). Taken

12 together, these data support the hypothesis that adenosine derived from CD39+

13 B cells suppresses the immune response after sepsis, at least in part, through

14 suppression of $\mathrm{M} \varphi$ microbial killing.

16 We then investigated whether B cell-derived adenosine induces IL-10 production

17 in M $\varphi$ s. Although septic $B$ cells enhanced $M \varphi$ production of IL-10 in response to

18 L. pneumophila infection, the addition of CD39i or ADA to the co-cultures

19 completely abrogated this effect, while ATPyS did not alter IL-10 levels (Figure

20 5I). Moreover, Entpd1\% septic B cells failed to increase IL-10 production by $L$.

21 pneumophila-infected M $\varphi$ S (Figure 5J), suggesting that the hydrolysis of ATP into

22 adenosine by $\mathrm{CD}_{3} 9^{+} \mathrm{B}$ cells induces the production of IL-10 by L. pneumophila-

23 infected M $\varphi$ s. Loss or inhibition of A2aR in L. pneumophila-infected M $\varphi$ s reduced

24 their production of IL-10 when co-cultured with septic B cells, but also with naïve

25 B cells or when cultured alone (Figures $5 \mathrm{~K}$ and $5 \mathrm{~L}$ ). Overall, our findings 
1 demonstrate that $B$ cell-derived adenosine suppresses bacterial killing by

2 inducing the production of IL-10 in M $\varphi s$.

4 To validate the relevance of our in vitro observations in vivo, we utilized IL-

$510^{+/ E G F P}$ reporter mice and found increased IL-10 expression by splenic M $\varphi$ s from

6 sepsis-surviving mice 15 days after CLP (Figure 5M). Moreover, sepsis-surviving

7 mice show robust IL-10 in lung tissue homogenates, which was reduced with

$8 \mathrm{~A} 2 \mathrm{aRi}$ or CD39i and in Adora2a ${ }^{-/}$and $\mu \mathrm{MT}^{-/-}$mice (Figure S5F). Sham and naive

9 mice had low levels of IL-10 in lung tissue homogenates (Figures S1G). Finally,

10 to investigate the role of $A 2 a R$ on $M \varphi s$ in developing sepsis-induced

11 immunosuppression, we induced CLP in Adora2a $a^{\Delta L y z 2}$ mice. Sepsis-surviving

12 Adora2a ${ }^{\triangle L y z 2}$ mice were resistant to L. pneumophila challenge 15 days post-CLP,

13 showing a lower number of L. pneumophila in the lung and spleen and reduced

$14 \mathrm{IL}-10$ in lung tissue homogenates than control mice (Figures 5N-5P). There was

15 no difference in CLP survival between $A d o r a 2 a^{\Delta L y z 2}$ or control mice with antibiotic

16 treatment (Figure $\mathrm{S} 2 \mathrm{H}$ ). Together, these data indicate that A2aR signaling on

$17 \mathrm{M} \varphi s$ is required for $\mathrm{IL}-10$ production and, consequently, for the immune 18 dysfunction in sepsis-surviving mice.

20 Metabolic reprogramming in septic B cells supports their suppressive 21 function

22 Given that septic B cells suppress $M \varphi$-mediated bacterial killing through ATP 23 hydrolysis into adenosine, we hypothesized a role for B cell metabolic 24 reprogramming induced by sepsis. To explore this possibility, we initially 25 assessed the extracellular acidification rate (ECAR) and oxygen consumption 
1 rate $(\mathrm{OCR})$ in isolated $C D 19^{+} B$ cells. Septic $B$ cells showed higher ECAR and

2 OCR than naive B cells, suggesting that septic B cells have increased glycolytic

3 flux and mitochondrial activity. We then utilized inhibitors of the metabolic

4 pathways required for ATP generation (Figure 6A). UK-5099, an inhibitor of the

5 mitochondrial pyruvate transporter, reduced all respiratory parameters in septic

6 B cells to similar levels found in naive B cells (Figures 6B-6E), demonstrating a

7 critical dependence on glycolysis for the increased mitochondrial respiratory

8 activity of septic B cells. Septic B cells had increased uptake of a fluorescent

9 glucose analog (2-NBDG) and higher mRNA expression of glycolytic related

10 genes Hif1a (hypoxia-inducible factor-1a), Hk1 and Hk2 (hexokinase-1 and 2,

11 respectively), compared to naive $B$ cells (Figures $6 \mathrm{~F}$ and $6 \mathrm{G}$ ). These data suggest

12 that septic B cells are metabolically reprogrammed toward aerobic glycolysis that

13 feeds the mitochondrial tricarboxylic acid (TCA) cycle.

We next investigated the impact of metabolic reprogramming of septic B cells on

ATP production. Consistent with increased glycolytic flux and mitochondrial

17 activity, unstimulated or IL-4-activated septic B cells contained more intracellular

18 ATP than naive B cells. The addition of glycolytic inhibitors 2-deoxyglucose (2-

19 DG), 3PO (PFKFB3 inhibitor), or echinomycin (HIF-1a inhibitor) reduced ATP

20 production in septic B cells to similar levels found in naive B cells. Likewise, the 21 addition of oligomycin (an inhibitor of mitochondrial ATP synthase) or rotenone

22 (an inhibitor of mitochondrial complex I) decreased ATP production in septic B 23 cells. However, ATP production in septic B cells was not affected by etomoxir (a 24 carnitine palmitoyltransferase-1a inhibitor) or BPTES (a glutaminase-1 inhibitor). 25 These results suggest that the enhanced mitochondrial activity and ATP 
1 production in septic B cells require glycolytic activity, but not glutaminolysis or

2 fatty acid oxidation (Figures $6 \mathrm{H}$ ). We then investigated if the increased metabolic

3 affected the extracellular release of ATP and found enhanced ATP release by

4 septic $B$ cells than naive $B$ cells, which was abrogated by inhibiting the pannexin-

51 ATP-permeable channel (Panx1) with CBX (Figures 6I and 6J).

7 Finally, to indirectly investigate the effect of metabolic reprogramming in 8 sustaining septic B cells' suppressive activity, peritoneal $M \varphi s$ from naive mice

9 were infected with L. pneumophila and co-cultured with B cells isolated from naive

10 or sepsis-surviving mice for $48 \mathrm{~h}$ with or without CBX. Panx1 inhibition by CBX

11 did not directly affect bacterial killing by $M \varphi s$ alone or in co-culture with naive $B$

12 cells. However, the CBX abrogated the inhibitory effect of septic $B$ cells on $M \varphi$

13 bacterial killing and reduced $\mathrm{M} \varphi \mathrm{s}$ production of $\mathrm{IL}-10$ (Figures $6 \mathrm{~K}-6 \mathrm{M}$ ).

14 Collectively, our findings suggest that septic B cells have a metabolic

15 reprogramming toward aerobic glycolysis that feeds mitochondrial TCA cycle, 16 supporting their suppressive activity by enhancing production and release of 17 ATP.

Septic patients have an expansion of $\mathrm{CD} 39^{+}$plasmablast and adenosine accumulation

21 To investigate the clinical relevance of our findings, we collected peripheral blood 22 samples from 21 septic patients and 36 age- and sex-matched healthy controls $23(\mathrm{HC})$. All patients presented clinical and laboratory variables that fulfilled sepsis 24 criteria (Table S1). As observed in septic mice, the frequency of $25 \mathrm{Ki}^{+}{ }^{+} \mathrm{CD} 39^{+} \mathrm{CD} 19^{+} \mathrm{B}$ cells was increased in septic patients compared to $\mathrm{HC}$ 
1 (Figure 7A). Naïve and memory B cells expressed intermediate levels of CD39 at

2 comparable frequencies between septic patients and HC (Figures 7B and 7C).

3 However, CD39 was highly expressed in plasmablasts, and septic patients

4 showed a higher frequency than $\mathrm{HC}$ (Figures 7B-7D). Sorted CD19+ B cells from

5 septic patients showed increased ecto-ATPase activity compared to HC, which

6 was inhibited by CD39i (Figure 7E). Inline, septic patients had higher plasma

7 adenosine concentrations than HC (Figure 7F). Dividing septic patients by illness

8 severity, adenosine levels were higher in patients with septic shock than sepsis

9 only (Figure 7G), as previously reported (Martin et al., 2000). Moreover, the ecto-

10 ATPase activity of isolated $\mathrm{CD} 19^{+} \mathrm{B}$ cells positively correlated with serum

11 adenosine concentration in septic patients (Figure $7 \mathrm{H}$ ), suggesting that the

12 elevated adenosine concentration was associated with CD39 activity in B cells.

14 To investigate whether human septic B cells could suppress monocytes' bacterial

15 killing capacity, sorted CD19+ $B$ cells from 3 different septic patients or healthy

16 volunteers were co-cultured with $\mathrm{CD}_{14}{ }^{+}$monocytes isolated from $\mathrm{HC}$ blood. We

17 assessed bacterial load by using an L. pneumophila strain stably expressing the

18 luxCDABE operon. Monocytes co-cultured with B cells from septic patients

19 contained more bacteria than those co-cultured with B cells from healthy

20 volunteers or monocytes alone. To address adenosine's contribution to bacterial

21 killing suppression, we added A2aRi or apyrase in culture. A2aRi improved

22 bacterial killing by monocytes, whereas apyrase impaired monocyte restriction of

23 bacterial replication, especially when co-cultured with septic B cells (Figure 7l).

24 L. pneumophila-driven IL-10 production by monocytes was enhanced by co- 
1 culture with B cells from septic patients but not healthy volunteers. This was

2 inhibited by A2aRi and further enhanced with the addition of apyrase (Figure 7J).

4 Finally, we analyzed publicly available single-cell RNA-seq data from PBMCs of 5 septic patients and controls (Reyes et al., 2020). Gene expression analysis

6 identified one distinct B cell population characterized by both high expression of 7 CD39 and plasmablast markers (MZB1, JCHAIN, FKBP11, SEC61G, VIMP, 8 ITM2C, IGHA1, and TXM). Similar to the CLP model, we found that septic patients 9 had a greater abundance of $\mathrm{CD} 9^{+}$plasmablast cells than the controls (no sepsis)

10 (Figures 7K and 7L). Furthermore, differential expression analysis of CD39+ 11 plasmablast cells against other $B$ cells revealed high expression of mitochondrial 12 genes and enrichment of genes participating in the metabolic TCA cycle, 13 respiratory electron transportation, detoxification of reactive oxygen species, and 14 glycolysis (Figures S6A and S6B). Overall, these results substantiate our findings 15 with experimental sepsis, showing an expansion of $\mathrm{CD} 9^{+}$plasmablasts with 16 immunosuppressive activity in septic patients. 


\section{DISCUSSION}

2 Inflammatory environments can induce differentiation and/or expansion of distinct

3 subsets of regulatory B cells that suppress pathological or protective immune 4 responses (Rosser and Mauri, 2015). Activated B cells can express CD39 and, 5 therefore, produce adenosine in the presence of extracellular ATP (Maliszewski 6 et al., 1994; Saze et al., 2013). Similar to Treg cells, CD39 expression contributes

7 to B cell suppressive function in vitro (Borsellino et al., 2007; Deaglio et al., 2007;

8 Figueiró et al., 2016; Peres et al., 2015; Saze et al., 2013); however, the

9 implications of this suppression remain underexplored. In this study, we report 10 that sepsis induced an expansion of a plasmablast population in mice and human 11 septic patients with elevated CD39 expression responsible for increasing 12 circulating extracellular adenosine. Adenosine derived from CD39-expressing B 13 cells suppressed the host immune response, rendering sepsis-surviving mice 14 highly susceptible to secondary infections induced by opportunistic human pathogens, A. fumigatus and L. pneumophila (Behnsen et al., 2008; Berjeaud et al., 2016).

18 Adenosine signaling mediated by $\mathrm{A} 2 \mathrm{aR}$ augments the production of antiinflammatory cytokines and suppresses microbial killing by neutrophils and M $\varphi s$ (Hasko et al., 2008; Haskó and Cronstein, 2013). Consistent with this, we found

21 that septic B cell-derived adenosine efficiently suppressed M $\varphi s$ killing ability and 22 the specific deficiency of A2aR in myeloid cells improved the resistance of sepsissurviving mice against secondary infections. These demonstrate the essential role of adenosine-producing $B$ cells in developing sepsis-induced immunosuppression by suppressing macrophage function. However, an 
1 unexpected finding was that IL-10, which has long been considered the central

2 suppressive mediator produced by regulatory B cells (Rosser and Mauri, 2015),

3 did not directly influence the suppressive activity of septic CD39+ B cells. Instead,

4 we found that $M \varphi s$ respond to adenosine from CD39-expressing B cells via A2aR

5 signaling by producing immunosuppressive IL-10 that impairs their bactericidal

6 activity. Indeed, it was previously reported that, in the absence of IL-10, a

7 CD39/CD73 pathway mediates the regulatory function of peritoneal B1 cells via

8 the production of adenosine (Kaku et al., 2014). This was further supported by

9 our observations that splenic B1a cells show a slight up-regulation of CD39

10 expression in sepsis-surviving mice. Thus, we cannot exclude the contribution of

$11 \mathrm{CD}^{1 / 0} \mathrm{~B} 1$ a cells working together with $\mathrm{CD} 39^{\text {hi }} \mathrm{CD} 138^{\mathrm{hi}}$ plasmablasts to the

12 immunosuppressive status observed in sepsis-surviving mice.

14 We found that septic B cells have a metabolic reprogramming toward aerobic 15 glycolysis that feeds mitochondrial TCA cycle with pyruvate enhancing production 16 and release of ATP. These findings are consistent with previous reports of 17 increased glycolysis and oxygen consumption rate by activated B cells with LPS 18 or IL-4 (Caro-Maldonado et al., 2014; Waters et al., 2018). We, therefore, propose 19 that the metabolic reprogramming in septic $\mathrm{CD} 9^{+} \mathrm{B}$ cells supports their 20 suppressive activity by enhancing the production and release of ATP.

22 In our study, antibiotic treatment of naive or sham-operated mice did not alter the 23 frequency of CD39-expressing B cells and plasma adenosine concentration. 24 Moreover, mice who survived to moderate sepsis receiving or not antibiotic 25 treatment were equally susceptible to the secondary infection, suggesting that 
1 antibiotic treatment does not directly impact sepsis-induced immune

2 dysregulation. However, it is very complicated to dissociate the consequences of

3 sepsis itself from the effect of sepsis treatment on the long-term immune

4 dysregulation found in sepsis survivors since all septic patients inevitably receive

5 antibiotic treatment. This is the reason why we have established a mouse model

6 of lethal CLP-induced sepsis followed by a short treatment with ertapenem, a

7 widely used antibiotic to treat critically ill patients with abdominal sepsis (Solomkin

8 et al., 2010), intending to reduce infection and mimicking the clinical scenario

9 (Nascimento et al., 2010). Future studies are required to determine whether the

10 expansion of $\mathrm{CD}_{39}{ }^{+} \mathrm{B}$ cells reported here is due to inflammation following sepsis

11 or a combination with changes in the microbiota by antibiotics.

$13 \mathrm{IL}-10$ has long been described as a major mediator of sepsis-induced 14 immunosuppression (Steinhauser et al., 1999). We have previously reported that 15 IL-33, released during the tissue injury following sepsis, induces activation of 16 ILC2s and the polarization of IL-10-secreting M2 macrophages that promote the 17 expansion of the Treg cell population in an IL-10-dependent manner, thereby 18 contributing to the development of sepsis-induced immunosuppression 19 (Nascimento et al., 2017). However, our current understanding of the primary IL20 10-secreting immune cells and the signaling that maintains IL-10 production in 21 sepsis survivors remains limited. This study addressed this gap, revealing that 22 adenosine-derived from $\mathrm{CD}_{39}{ }^{+} \mathrm{B}$ cells is an essential mediator that triggers IL2310 production by macrophages in sepsis-surviving mice, thus fitting the pieces of 24 the intricate mechanism underlying the persistent dysregulation of the host 25 immune response in sepsis survivors. However, we did not investigate the 
1 mechanism by which sepsis induces the expansion of $\mathrm{CD}_{3} 9^{+} \mathrm{B}$ cells. In this

2 regard, IL-33 was shown to induce a subset of IL-10-producing regulatory B cells

3 (Sattler et al., 2014). Based on our previous study (Nascimento et al., 2017), IL-

433 might have a potential involvement, but we cannot exclude the participation of

5 other cytokines or gut-microbiota-derived metabolites (Rosser et al., 2020;

6 Yoshizaki et al., 2012). Therefore, future studies are necessary to identify the

7 mechanism underlying the $\mathrm{CD} 39^{+} \mathrm{B}$ cell expansion induced by sepsis.

9 In summary, our results revealed a suppressive function of CD39+ plasmablasts 10 that is responsible, at least in part, for the long-term immunosuppression 11 observed in sepsis survivors by generating a high amount of extracellular 12 adenosine. These findings fill gaps in the current knowledge of the mechanism underlying the persistent dysregulation of the host immune response in sepsis 14 survivors.

\section{LIMITATIONS OF THE STUDY}

17 We demonstrated that the metabolic reprogramming in septic CD39+ 18 plasmablasts supports their suppressive activity by enhancing ATP production.

19 However, extracellular ATP can be released by some bacteria from mouse and 20 human feces (Mempin et al., 2013). Future studies are needed to determine 21 whether perturbation of gut microbiota following sepsis might affect the systemic 22 bioavailability of extracellular ATP and adenosine production by CD39+ $\mathrm{B}$ cells. 23 In addition, although we provided preliminary evidence showing that $24 \mathrm{CD} 9^{\text {hi }} \mathrm{CD} 138^{\text {hi }} \mathrm{B}$ cells are enriched in the transitional 1 population, further 
1 studies are needed to better characterize where exactly these cells reside in the

2 spleen.

\section{Acknowledgments}

5 We thank leda Schivo, Sergio Rosa, Ana Katia Santos, Denise Ferraz and Marc

6 Le Bert for technical assintances. This work was supported by Sao Paulo

7 Research Foundation (FAPESP) grant (2013/08216-2 - Center for Research in

8 Inflammatory Diseases), National Council for Scientific and Technological

9 Development (CNPq) grant (483659/2013-4), FAPESP fellowships for D.C.N.

10 (2012/10100-0 and 2015/25974-3) and European funding in Region Centre-Val

11 de Loire grants (FEDER 2016-00110366, EX005756 and EUROFéRI

12 EX010381).

\section{Author Contributions}

15 D.C.N. planned and performed experiments, analysed data and wrote the manuscript. J.C.A-F planned experiments, analyzed data, wrote the manuscript and supervised the project. B.R., F.Q.C., V.Q., and T.M.C. planned and analyzed experiments. P.R.V., R.G.F., A.R.P., P.H.M., P.B.D., F.P.V., R.S.P., J.E.T-K., D.C., M.A.D and J.A.R.P performed and analyzed experiments. D.Z. and M.C.B. provided human samples and analyzed data. L.M-S and D.M.F performed flow cytometry experiments and analyzed t-SNE data. A.E.R.O., Í.M.S.C., and H.I.N. re-analyzed public datasets. G.K. provided Entpd1/- mice and analyzed data. J.L. provided Adora2a ${ }^{\mathrm{f} / \mathrm{f}}$ mice and analyzed data. D.S.Z. provided reagents and analyzed data. 


\section{Competing Interests statement}

2 The authors declare no competing interests.

3

4 Inclusion and diversity

5 We worked to ensure gender balance in the recruitment of human subjects. One

6 or more of the authors of this paper self-identifies as an underrepresented ethnic

7 minority in science. One or more of the authors of this paper self-identifies as a

8 member of the LGBTQ+ community.

9 


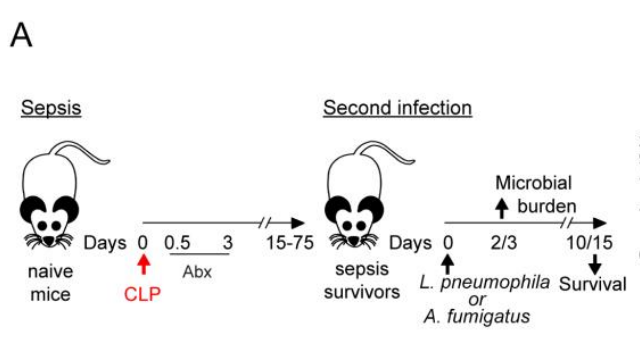

B Sepsis

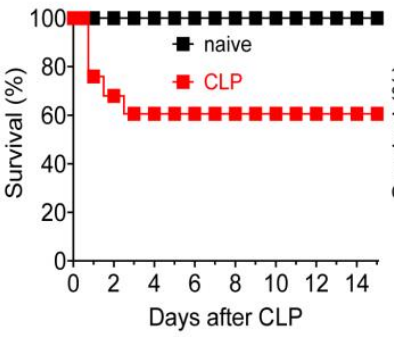

C Second infection

Figure 1
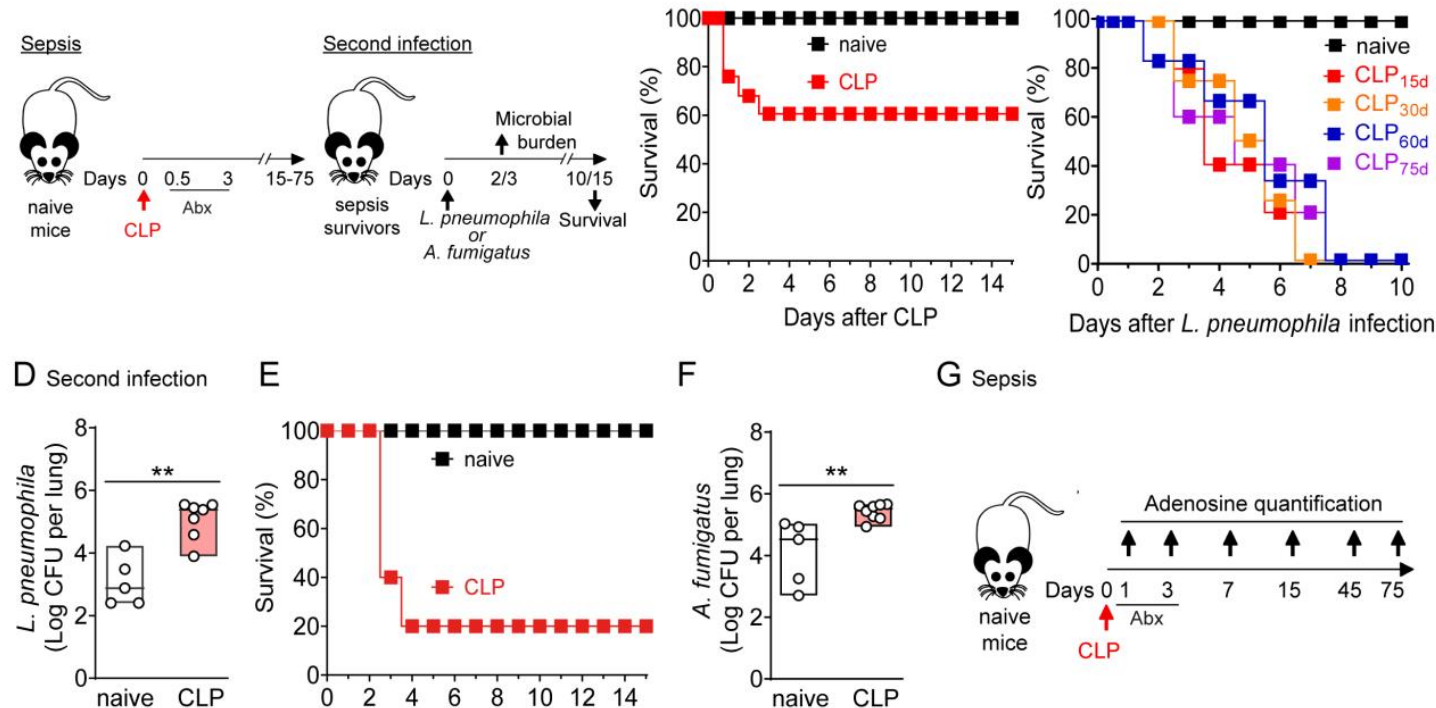

E

F

G Sepsis
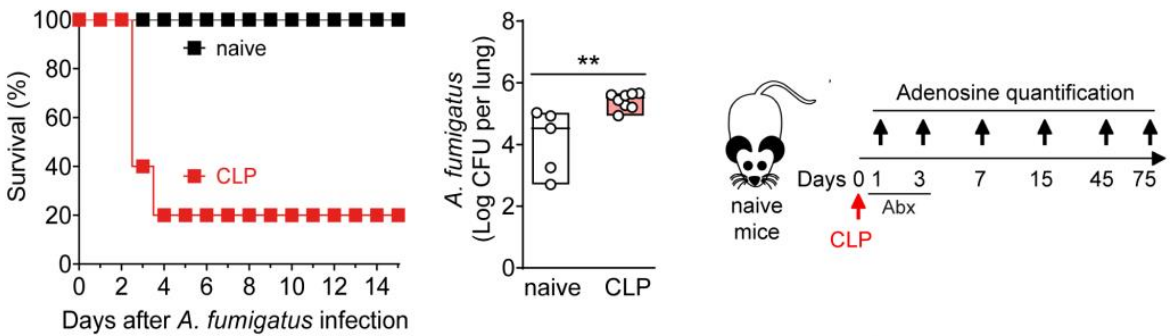

H Plasma adenosine

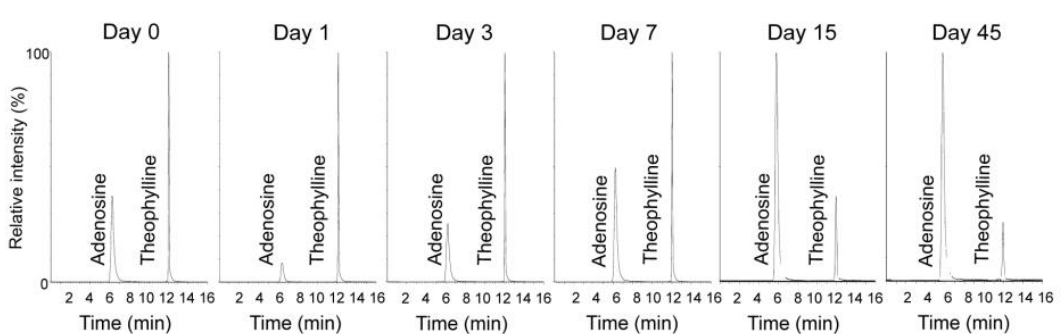

Time (min)

Time (min)

Time (min)

Time ( $\mathrm{min}$ )

$\mathrm{K}$ Second infection

- naive+vehicle/naive+A2aRi

들 CLP+vehicle 들 CLP+A2aRi
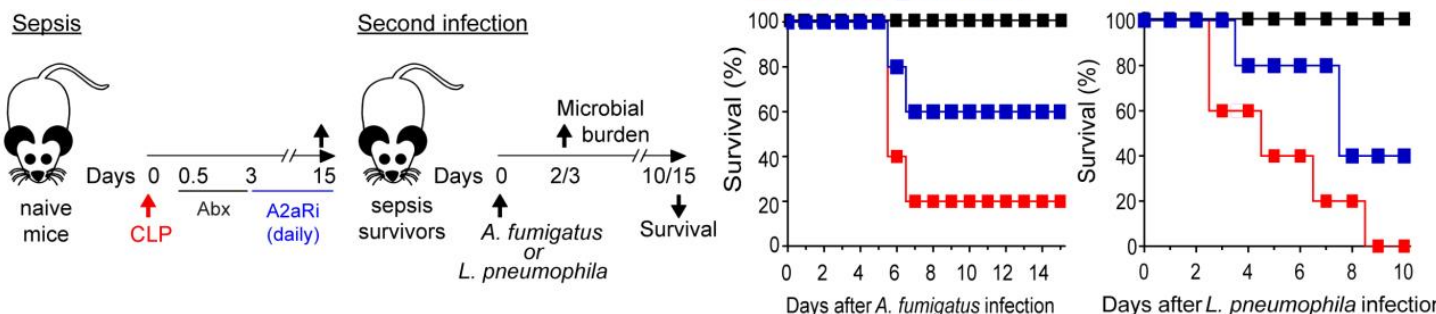

$\mathrm{L}$ Second infection

$$
\square \text { vehicle }
$$

M

$$
\square \text { WT }
$$

$\square$ Adora2a-/-
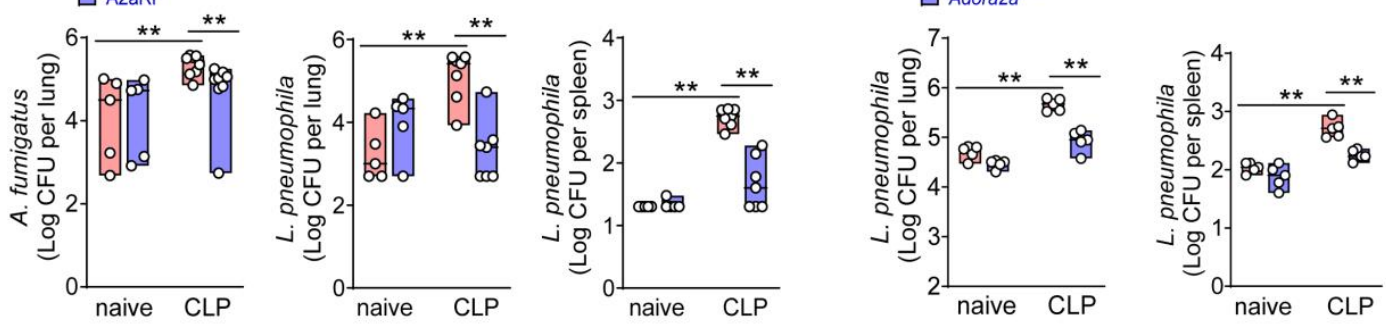
Figure 2

A spleen cells

B Spleen cells

C
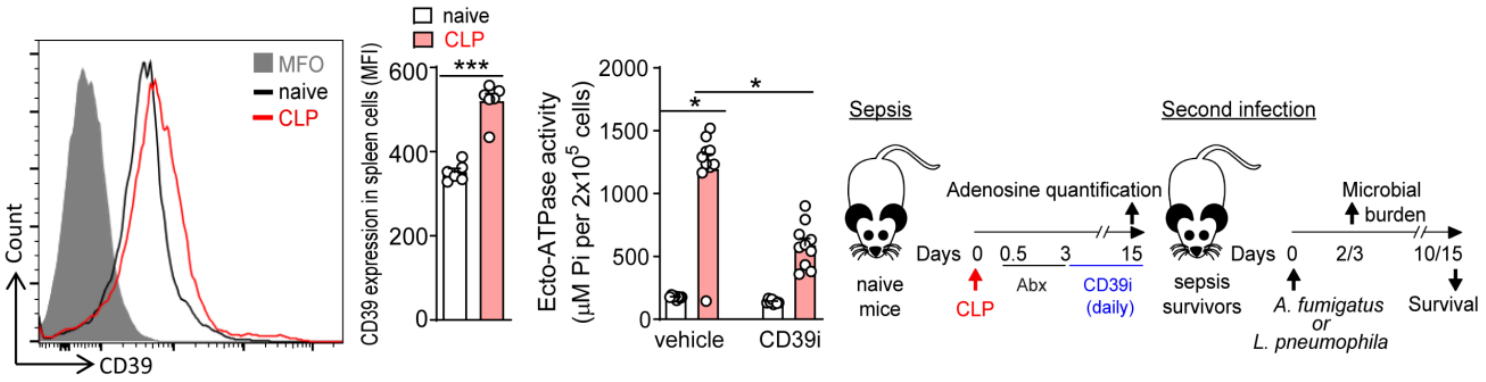

D Plasma adenosine

E
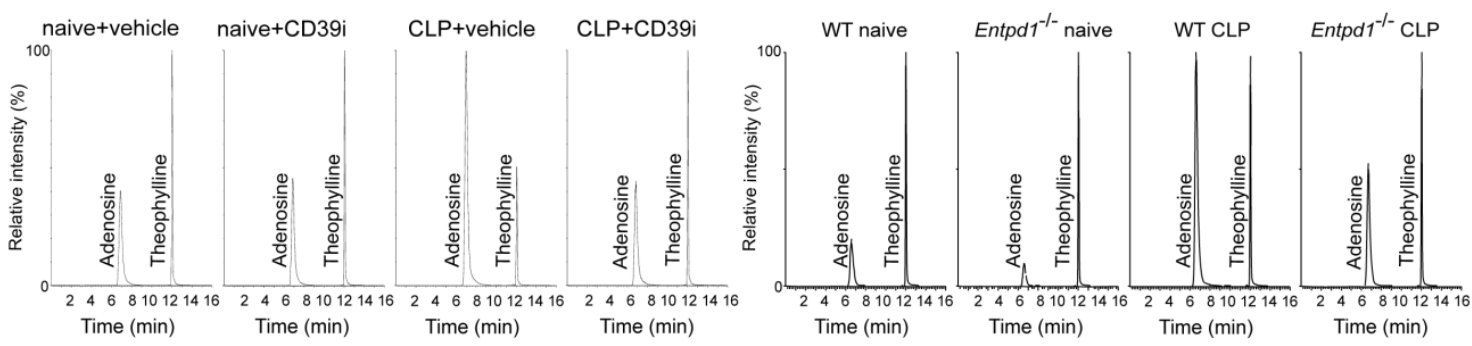

F

G Second infection
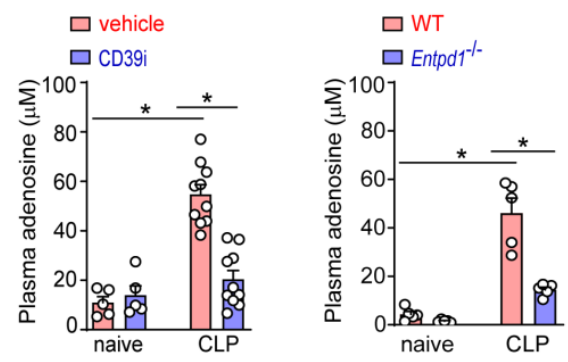

- naive+vehicle/naive+CD39i

- CLP+vehicle $=\mathrm{CLP}+\mathrm{CD} 39 \mathrm{i}$
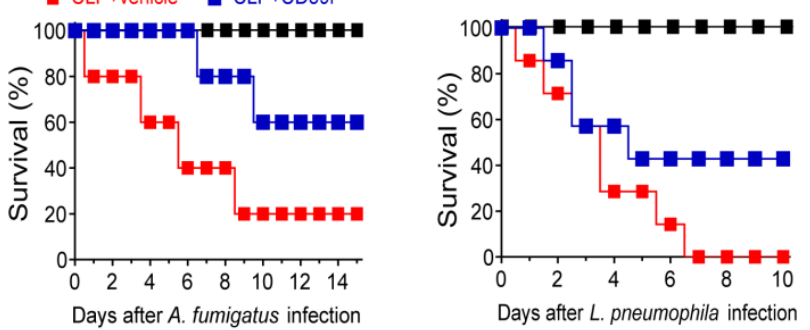

$\mathrm{H}$ Second infection

।

J
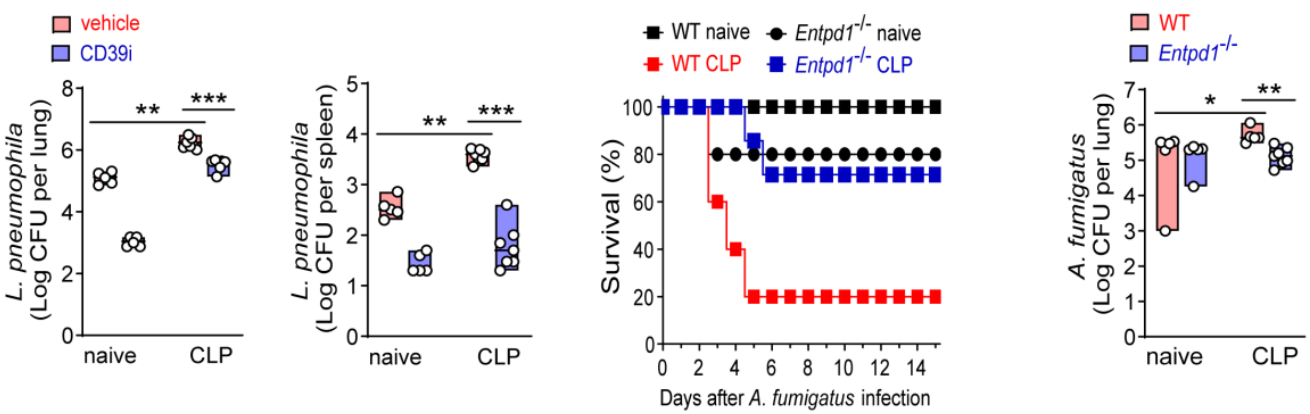


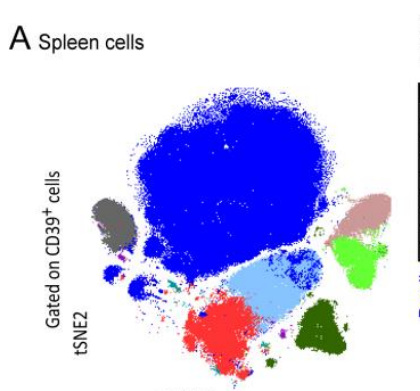

tSNE1

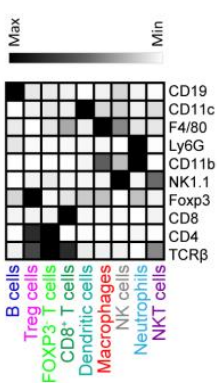

音
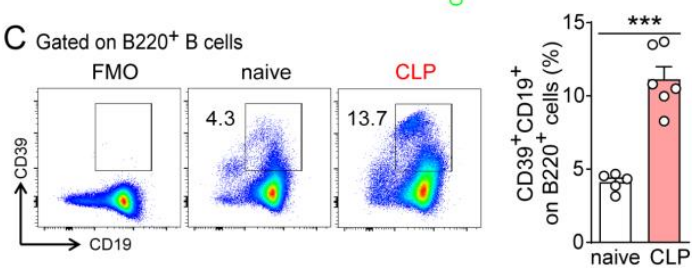

E

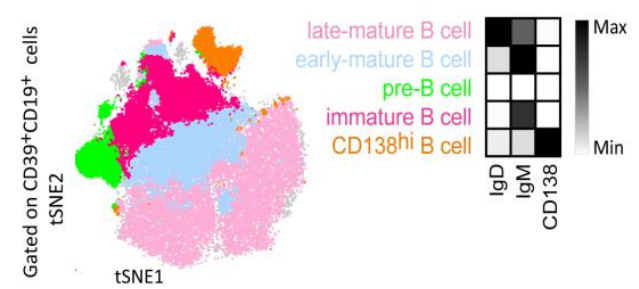

$\mathrm{H}$

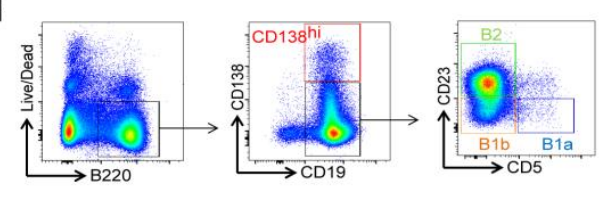

I

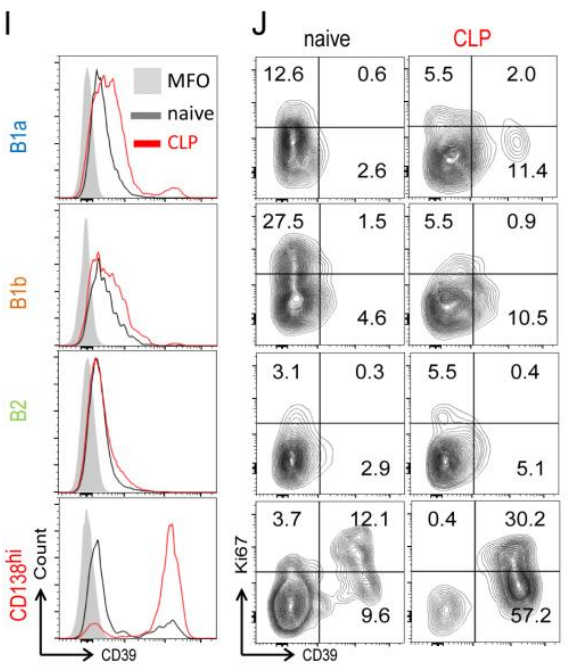

B

Figure 3

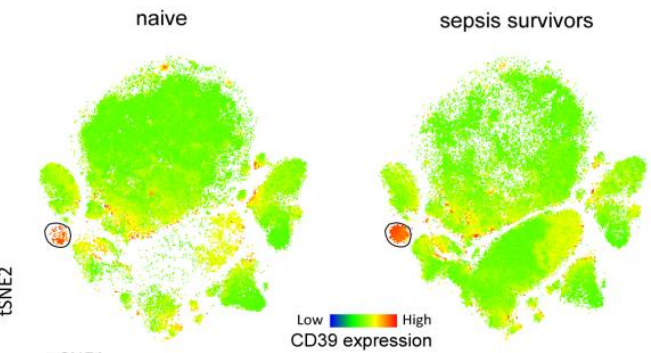

tSNE1

$D$ Gated on $\mathrm{CD} 19^{+} \mathrm{B}$ cells
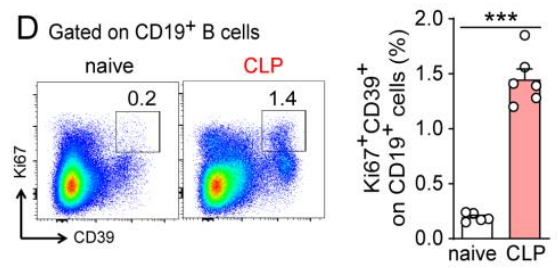

F

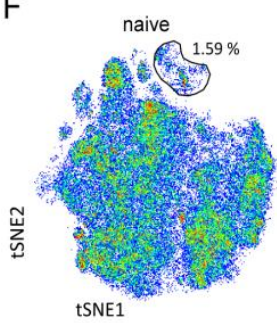

sepsis survivors

G<smiles></smiles>

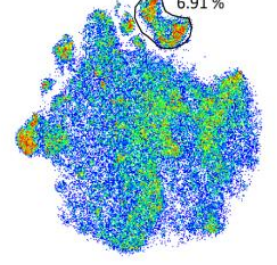

sepsis survivors

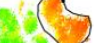

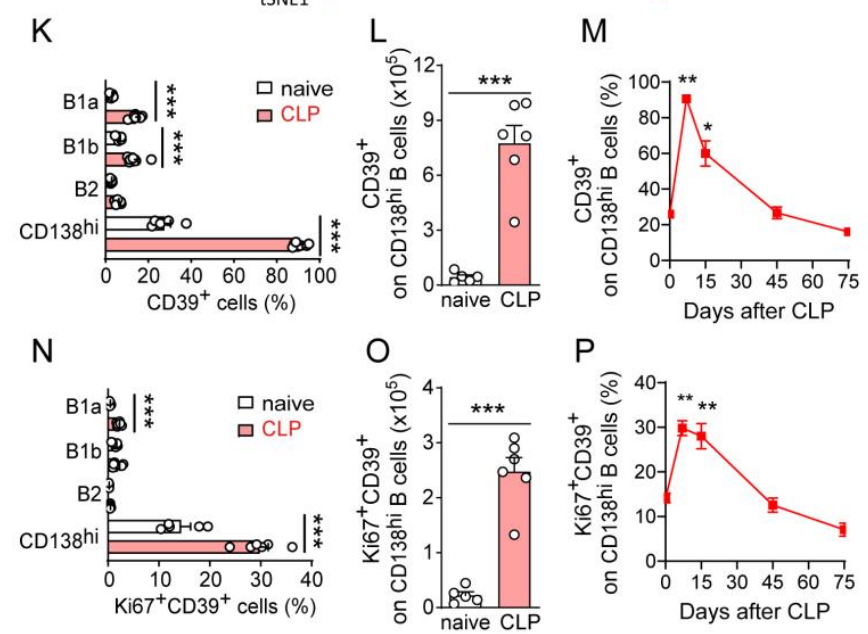


A sorted $\mathrm{CD} 19^{+} \mathrm{B}$ cells $\mathrm{B}$

C
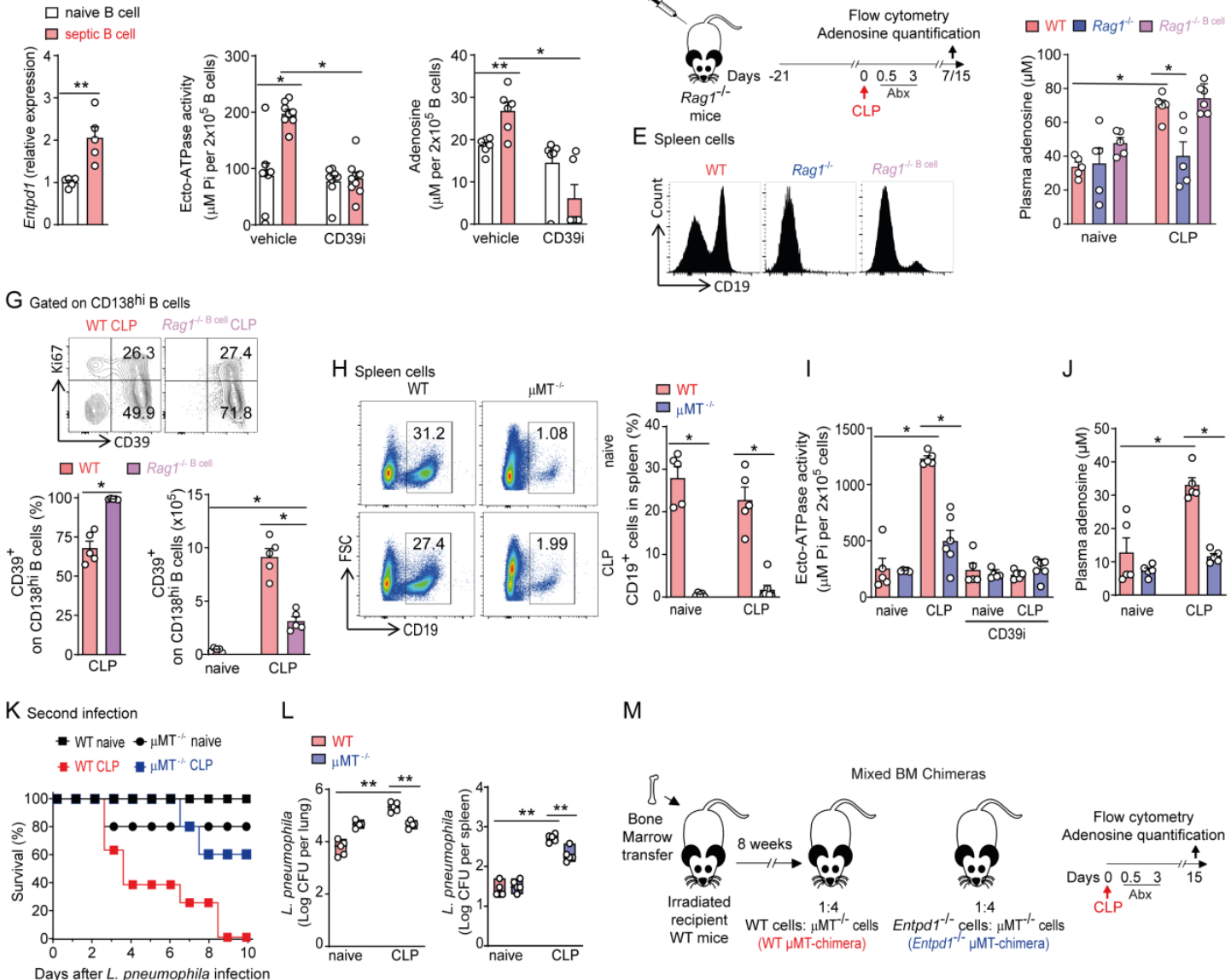

L

$\square \mathrm{WT}$
$\square \mu \mathrm{MT}$
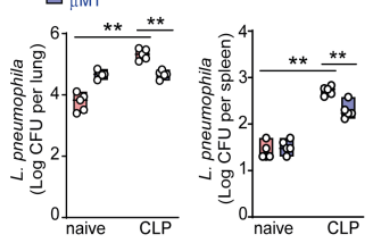

Bone
Marrow
transfer

$\mathrm{N}$ Spleen cells

MFO

- WT $\mu \mathrm{MT}$-chimera ]naive

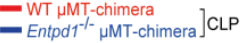

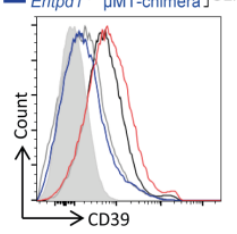

1 transfer

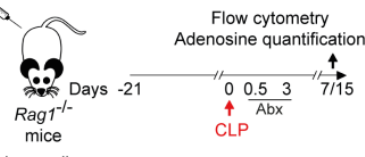

E Spleen cells

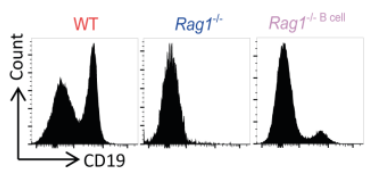

F

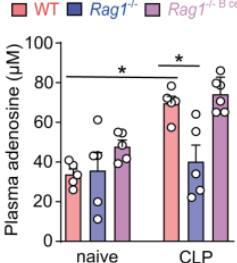

$J$
M

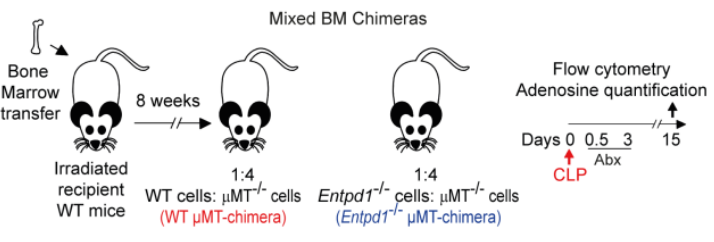

P

Q

$\mathrm{R}$

naive Macrophages

L. pneu

$\square$ WT $\mu$ MT-chimera

$\square$ Entpd1 ${ }^{-/-} \mu \mathrm{MT}$-chimera
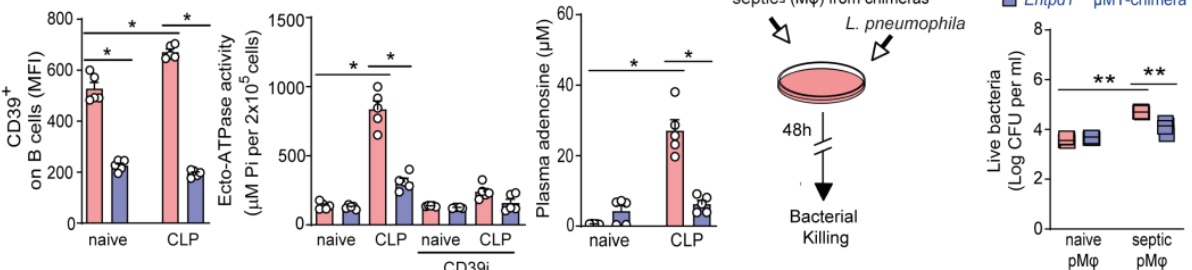
A

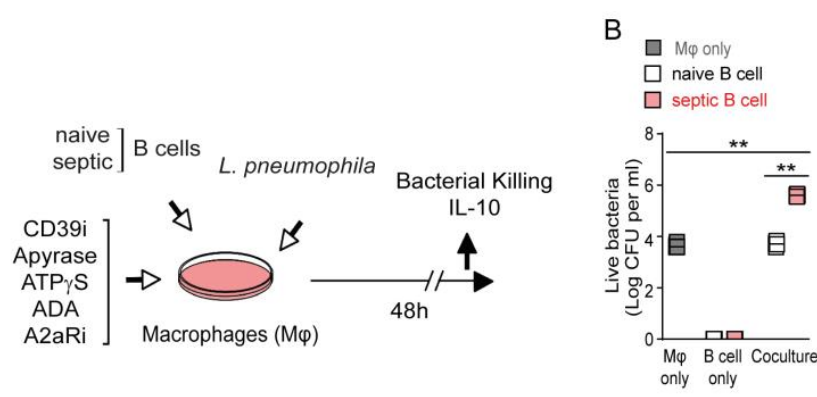

E

F
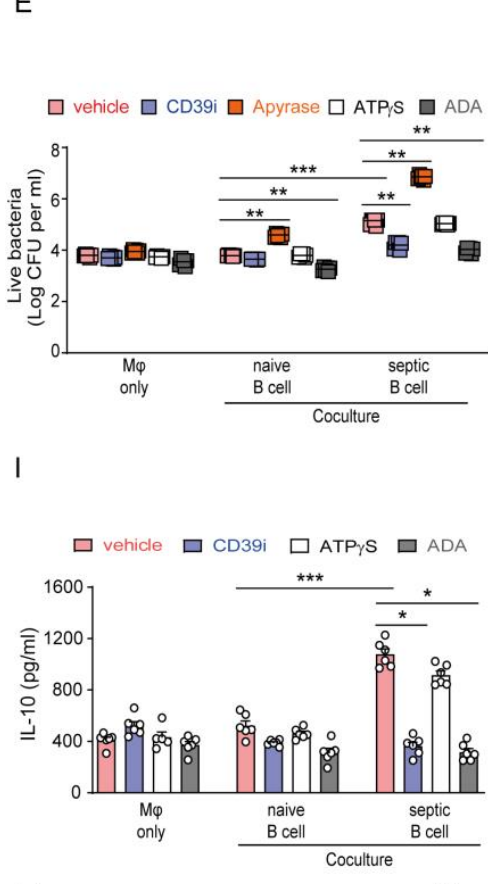

$M_{\text {Sepsis }}$

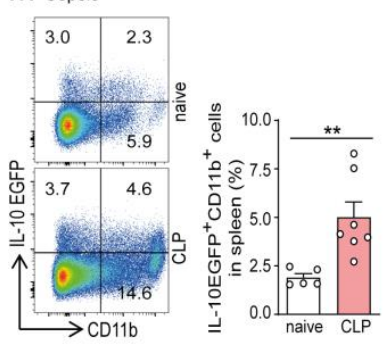

$\mathrm{N}$ Second infection

- Adorazaff naivelAdoraza ${ }^{\mathrm{Al} y z 2}$ naive - Adoraza navelAdorazad a

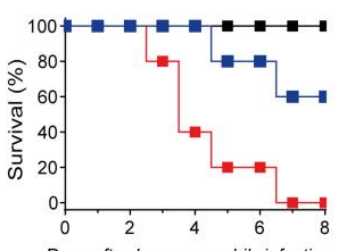

Days after $L$. pneumophila infection

G

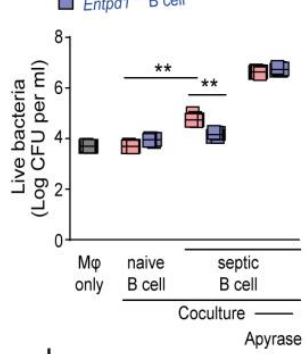

J

0

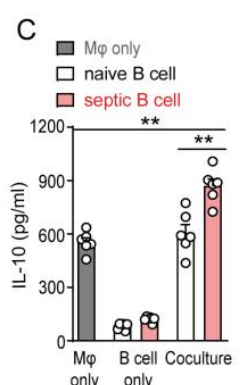

D

Figure 5

$\square M \varphi W T$

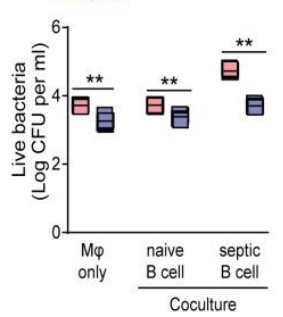

$\mathrm{H}$

$\square$ naive $\operatorname{CD} 39^{+} \mathrm{B}$ cell

a septic $\mathrm{CD}^{2} 9^{+} \mathrm{B}$ cell

$\square$ naive $B$ cell $\quad \square$ naive $\operatorname{CD} 39^{-} B$ cell
$\square$ septic B cell $\quad \square$ septic $\operatorname{CD} 39^{-} B$ cell

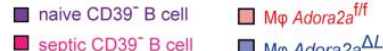

$\square \mathrm{M \varphi}$ Adora2a $a^{\Delta L y z 2}$
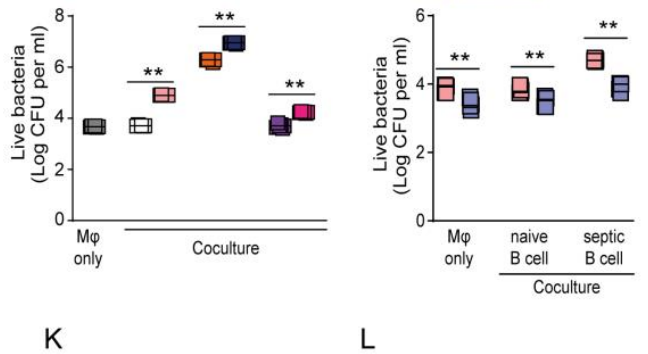

L

$\square$ vehicle

口A2aRi

$\square$ M Adoraza $^{\mathrm{fft}}$

$\square$ M 4 Adora2a $\triangle L y z 2$
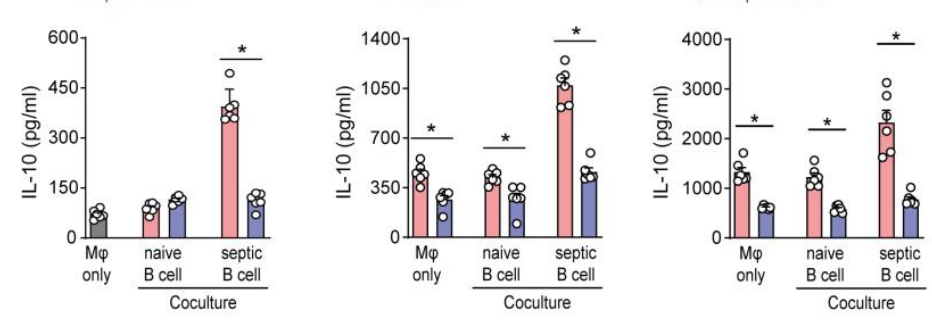

$\mathrm{P}$

$\square$ Adoraz $\mathrm{ff}^{\mathrm{ff}}$ $\square$ Adoraza ${ }^{\Delta l y z 2}$

$\square$ Adora2a $\mathrm{a}^{\mathrm{ff}} \mathrm{Adyz}$
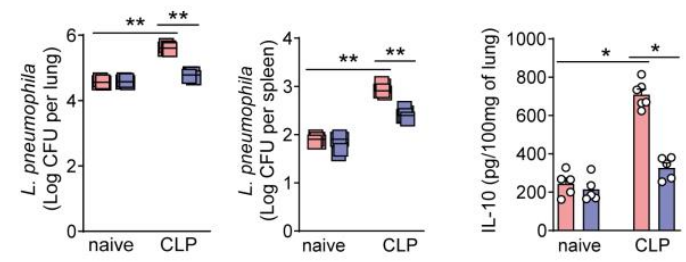
A

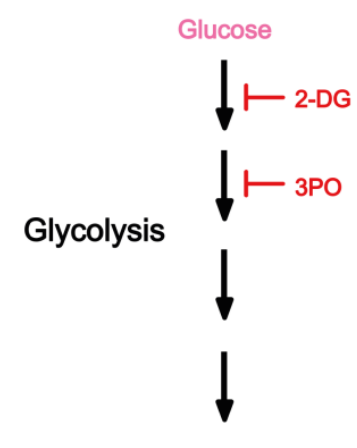

Lactate $\longleftarrow$ Pyruvate
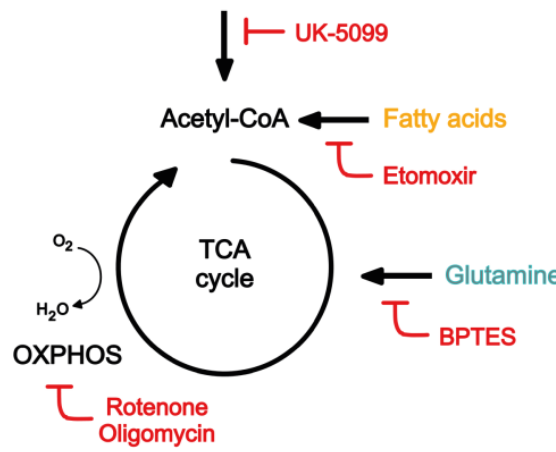

HIF1 $\alpha \vdash$ Echinomycin

$\mathrm{H}$

$\square$ naive B cell
$\square$ septic B cell
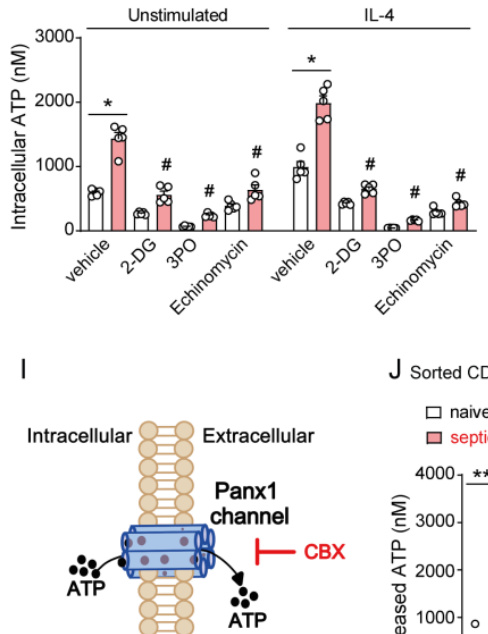

2

3

4

5

6
B Sorted CD $19^{+} \mathrm{B}$ cells

$\rightarrow$ naive B cell $\quad \rightarrow$ septic B cell

${ }^{40} 7$ Basal 'Glucosé Oligo :2-DG

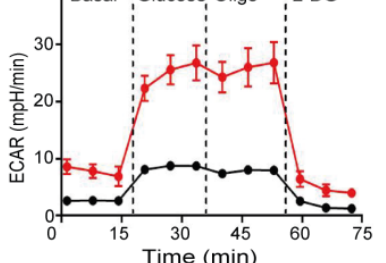

E

$\square$ naive B cell $\square$ septic B cell

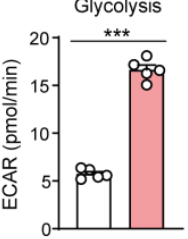

$\square$ naive B cell $\square$ septic B cell $\square$ septic B cell + UK-5099

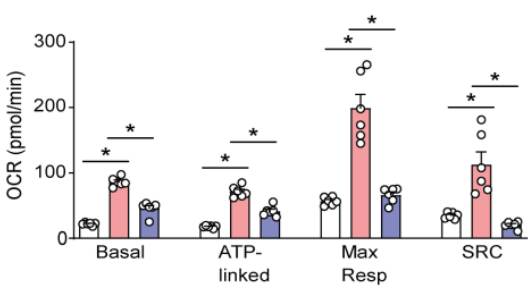

$\mathrm{F}$ Spleen cells

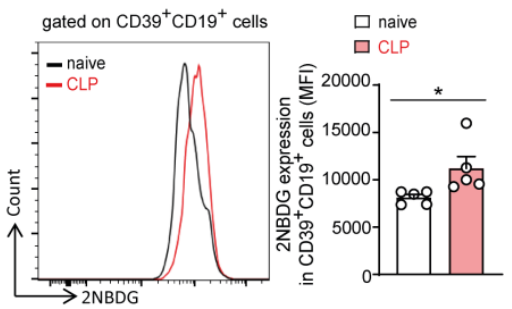

C

naive B cell $\quad-$ septic B cell

${ }^{400}$ Basal

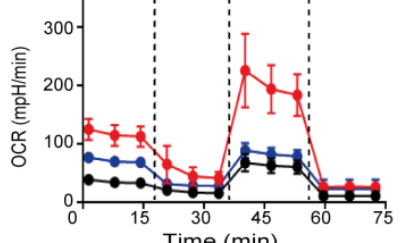

Figure 6 


\section{FIGURE LEGENDS}

2 FIGURE 1: Adenosine mediates sepsis-induced immunosuppression 3 through A2aR

4 (A) Schematic representation of sepsis-induced immunosuppression model (B-

5 F) (also see STAR Methods).

6 (B) Survival curves after CLP. Naive $\mathrm{n}=10$ and $\mathrm{CLP} \mathrm{n}=30$.

7 (C) Survival curves of naive or CLP-surviving mice after L. pneumophila infection. $8 \quad \mathrm{n}=5-8$.

9 (D) Bacterial load in the lungs of naive or CLP-surviving mice 2 days after $L$. 10 pneumophila infection. $\mathrm{n}=5-7$.

11 (E) Survival curves of naive or CLP-surviving mice after A. fumigatus infection. $12 \mathrm{n}=5$.

13 (F) Fungal load in the lungs of naive or CLP-surviving mice 3 days after $A$. 14 fumigatus infection. $\mathrm{n}=5-8$.

15 (G) Schematic representation of the experimental protocol for quantification of 16 plasma adenosine after CLP.

17 (H) Representative HPLC chromatograms and (I) concentrations of plasma 18 adenosine of naive or CLP-surviving mice. $n=5-20$.

19 (J) Schematic representation of sepsis-induced immunosuppression model with 20 A2aR antagonist [A2aRi, 8-(3-Chlorostyryl)-caffeine, $1 \mathrm{mg}^{\mathrm{kg}} \mathrm{kg}^{-1}$ ] treatment (K-L) 21 (also see STAR Methods).

22 (K) Survival curves of CLP-surviving mice after A. fumigatus or L. pneumophila 23 infections. $n=5$.

24 (L) Pathogen load in the lungs of CLP-survivors after $A$. fumigatus infection and 25 in lungs and spleen after $L$. pneumophila infection. $n=5-8$.

26 (M) Bacterial load in the lungs and spleens of CLP-surviving WT and Adora2a-27 mice after $L$. pneumophila infection. $n=5$.

28 Data are representative of 2-3 independent experiments. ${ }^{* *} p<0.01,{ }^{* \star *} p<0.001$. 29 Mantel-Cox log-rank test in B, C, E, K; one-way ANOVA with Dunnett posthoc 30 tests in I; and Mann-Whitney $\mathrm{U}$ test in D, F, L, M.

FIGURE 2: CD39 is required for sepsis-induced immunosuppression

33 (A-B) Splenic cells from CLP-surviving mice were harvested 15 days after CLP. 
1 (A) Histogram and mean fluorescence intensity (MFI) of CD39 expression in total 2 splenic cells. $n=6$.

3 (B) Ecto-ATPase activity of splenic cells cultured \pm CD39 inhibitor (CD39i, ARL $4 \quad 67156,200 \mu \mathrm{M}) . \mathrm{n}=8-10$.

5 (C) Diagram of sepsis-induced immunosuppression model with CD39i (2 mg.kg-

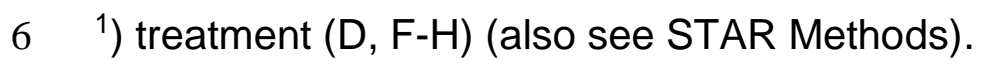

7 (D-E) Representative HPLC chromatograms and (F) concentrations of plasma 8 adenosine of naïve or CLP-surviving WT, Entpd1 ${ }^{-/}$or CD39i-treated mice. $\mathrm{n}=5$ 910.

10 (G) Survival curves of CLP-surviving WT, Entpd1 ${ }^{-/-}$or CD39i-treated mice after $A$.

11 fumigatus or L. pneumophila infection. $\mathrm{n}=5-7$.

12 (H) Bacterial load in the lungs and spleens of naive or CLP-surviving mice after 13 L. pneumophila infection. $\mathrm{n}=5-7$.

14 (I) Survival curves of CLP-surviving WT or Entpd1 ${ }^{-/-}$mice after A. fumigatus 15 infection. $\mathrm{n}=5-7$.

16 (J) Fungal load in the lungs of CLP-surviving WT or Entpd1 1 - mice after $A$. 17 fumigatus infection. $\mathrm{n}=5-7$.

18 Data are representative of 2-3 independent experiments. ${ }^{*} p<0.05,{ }^{* *} p<0.01$, $19{ }^{* * *} p<0.001$. Two-tailed unpaired Student's t-test in A, B, F; Mantel-Cox log-rank 20 test in $\mathrm{G}, \mathrm{I}$; and Mann-Whitney $\mathrm{U}$ test in $\mathrm{H}, \mathrm{J}$.

\section{FIGURE 3: Expansion of a CD39+ $B$ cell subset in sepsis-surviving mice}

(A-P) Splenic cells from CLP-surviving mice were harvested 7 or 15 days after CLP.

(A) Unsupervised analysis of single live $\mathrm{CD} 39^{+}$cells from the flow cytometry dataset of splenic immune cells of naïve and sepsis-surviving mice 15 days after CLP, using the t-SNE algorithm as described in STAR Methods. $n=10$.

(B) Heatmap density plots with MFI of CD39 expressed in different cell lineages with a blue-green-yellow-red continuous color scale. Naive $n=5$ and $\operatorname{CLP} n=5$. (C-D) Representative flow cytometry plots and bar graph showing (C) the frequency of splenic $\mathrm{CD} 39^{+} \mathrm{CD} 19^{+}$on gated $\mathrm{B} 220^{+} \mathrm{B}$ cells or (D) $\mathrm{Ki}^{2} 7^{+} \mathrm{CD} 39^{+}$on $C D 19^{+} B$ cells from naïve and sepsis survivors 7 days after CLP. $n=5-6$.

33 (E-G) Unsupervised analysis of single live $\mathrm{CD} 39^{+} \mathrm{CD} 19^{+} \mathrm{B}$ cells from the flow 34 cytometry dataset of immune cells in the spleen of naïve and sepsis-surviving 
1 mice 15 days after CLP, using the t-SNE algorithm as described in STAR 2 Methods.

3 (E) t-SNE maps color-coded according to manually gated clusters of distinct $4 \quad$ CD39 $+B$ cell subsets. $n=10$.

5 (F) t-SNE maps color-coded according to cell density cluster of distinct CD39+ B 6 cell subsets. Naive $\mathrm{n}=5$ and $\operatorname{CLP} \mathrm{n}=5$.

7 (G) t-SNE maps color-coded according to the MFI of CD39 expression intensity 8 in distinct $B$ cell subsets. Naive $n=5$ and $\operatorname{CLP} n=5$.

9 (H-P) B cell subset gating strategy. B1a (CD138 $\left.{ }^{\circ} \mathrm{CD}^{-} 3^{-} \mathrm{CD}^{+}\right)$, B1b (CD138-CD23$\left.10 \mathrm{CD}^{\circ}\right)$, and $\mathrm{B} 2\left(\mathrm{CD}^{-3} 8^{-} \mathrm{CD} 5^{-} \mathrm{CD}^{-} 3^{+}\right)$and plasmablast $\left(\mathrm{CD} 138^{\text {hi }}\right)$ cells among 11 viable $\mathrm{B} 220^{+} \mathrm{CD} 19^{+}$cells.

12 (I) Histogram of CD39 expression in B1a, B1b, B2, and plasmablast cells from 13 naïve and sepsis survivors 7 days after CLP. $n=5-6$.

$14(\mathrm{~J}, \mathrm{~K})$ Representative flow cytometry plots and graph bars showing the frequency 15 of CD39 expression in $B$ cell subsets from naive and sepsis survivors 7 days after 16 CLP. $n=5-6$.

17 (L) The absolute number of $\mathrm{CD} 39^{+} \mathrm{CD} 138^{\text {hi }}$ cells. $\mathrm{n}=5-6$.

18 (M) Frequency of $\mathrm{CD} 39{ }^{+} \mathrm{CD} 138^{\text {hi }}$ cells. $\mathrm{n}=5-6$.

19 (J, N) Representative flow cytometry plots and graph bars showing the frequency 20 of Ki67 and CD39 expression in B cell subsets from naive and sepsis survivors 7 21 days after CLP. $n=5-6$.

22 (O) The absolute number of $\mathrm{Ki} 67^{+}{ }^{\mathrm{CD}} 39^{+} \mathrm{CD} 138^{\text {hi }}$ cells. $\mathrm{n}=5-6$.

23 (P) Frequency of Ki67 ${ }^{+} \mathrm{CD} 39^{+} \mathrm{CD} 138^{\text {hi }}$ cells. $\mathrm{n}=5-6$.

24 Data are representative of 2-3 independent experiments. ${ }^{*} p<0.05,{ }^{* *} p<0.01$, $25{ }^{* * *} \mathrm{p}<0.001$. Two-tailed unpaired Student's t-test in C, D, K, N, L, O and one-way 26 ANOVA with Dunnett posthoc tests in M, P.

FIGURE 4: CD39+ $B$ cells promotes immunosuppression in sepsis-surviving mice

30 (A-C) Splenic CD19+ B cells were isolated from CLP-surviving mice 15 days after 31 CLP.

32 (A) mRNA expression of Entpd1. $\mathrm{n}=5$.

33 (B) Ecto-ATPase activity \pm CD39i. $n=8-9$.

34 (C) Concentration of adenosine in the cell culture supernatant. $n=6$. 
1 (D) A diagram of $B$ cell transfer into Rag ${ }^{-/}$mice following by sepsis-induced 2 immunosuppression model (E-G) (also see STAR Methods).

3 (E) Flow cytometry analysis of $\mathrm{CD} 19^{+}$splenic cells from WT, Rag $1^{-1-}$ and Rag 1- $^{-1-}$ 4 B cell (B cell transferred) mice 15 days after CLP. $n=5-7$.

5 (F) Plasma adenosine concentrations from sepsis survivors 15 days after CLP. $6 \quad \mathrm{n}=5-7$.

7 (G) Representative flow cytometry plots and graph bars showing the frequency

8 and the absolute number of splenic $C D 39^{+} C D 138^{\text {hi }} B$ cells from sepsis survivors

97 days after CLP. $n=5$.

10 (H-L) Sepsis-surviving WT and $\mu \mathrm{MT}^{-} /$mice were challenged with L. pneumophila 1115 days after CLP.

12 (H) Representative flow cytometry plots and graph bars showing the frequency 13 of splenic CD19+ $\mathrm{B}$ cells from WT and $\mu \mathrm{MT}^{-}{ }^{-}$mice 15 days after CLP. $\mathrm{n}=5-7$.

14 (I) Ecto-ATPase activity in splenic cells from WT and $\mu \mathrm{MT}-\%$ mice cultured \pm CD39i. $15 \mathrm{n}=5-6$.

(J) Plasma adenosine concentration in WT and $\mu \mathrm{MT} \%$ mice 15 days after CLP. $17 \mathrm{n}=5$.

(K) Survival curves of WT and $\mu \mathrm{MT}^{-/}$mice after $L$. pneumophila infection. $\mathrm{n}=5-8$.

(L) Bacterial loads in the lungs and spleens from WT and $\mu \mathrm{MT}^{-1}$ mice after $L$. 20 pneumophila infection. $\mathrm{n}=5$.

21 (M) A diagram of mixed bone marrow (BM) cells reconstitution in irradiated recipient all mice following by sepsis-induced immunosuppression model (N-P)

23 (also see STAR Methods).

24 (N) Histogram and MFI of CD39 expression on CD19+ $B$ cells. $n=5$.

(O) Ecto-ATPase activity of splenic cells cultured in \pm CD39i. $n=5$.

26 (P) Plasma adenosine concentration. $\mathrm{n}=5$.

27 (Q) A diagram of peritoneal macrophages $(M \varphi)$ from naive or sepsis-surviving chimeras exposed to $L$. pneumophila in vitro for analysis of killing assay.

29 (R) The number of viable bacteria recovered from $M \varphi$ lysates. $n=5$.

30 Data are representative of 2-3 independent experiments. ${ }^{*} p<0.05,{ }^{* *} p<0.01$

31 Two-tailed unpaired Student's t-test in A-C, G-H, J, N-P; one-way ANOVA with 32 Bonferroni posthoc tests in F, I; Mantel-Cox log-rank test in K; and Mann-Whitney 33 U test in $\mathrm{L}, \mathrm{R}$. 
1 FIGURE 5: Septic B cell-derived adenosine impairs macrophage bacterial

2 (A) Schematic representation of bacterial killing and IL-10 production analysis by

3 M $\varphi s$ co-cultured with naive or septic B cells in the presence of $L$. pneumophila 4 determined after 48h (B-L) (also see STAR Methods). Naive peritoneal macrophages were pooled from 5 naive mice and $B$ cells were isolated from naïve

6 or CLP-surviving mice. $\mathrm{n}=6$.

7 (B) The number of viable bacteria recovered from cell lysates.

8 (C) Concentrations of IL-10 in cell supernatant.

9 (D) The number of viable bacteria recovered from lysates of naive WT and $1 / 10^{-1-}$ 10 macrophages and/or naive or septic $B$ cells.

11 (E-F) The number of viable bacteria recovered from lysates of naive 12 macrophages with naive or septic Entpd1\% or WT B cells in the presence of 13 CD39i, Apyrase (20 U.mL $\left.{ }^{-1}\right)$, ATPyS $(100 \mu \mathrm{M})$, ADA (4 U.mL $\left.{ }^{-1}\right)$.

14 (G) The number of viable bacteria recovered from lysates of naive macrophages 15 and/or naive or septic CD39+ or CD39- B cells.

$16(\mathrm{H})$ The number of viable bacteria recovered from lysates of naive, Adora2a ${ }^{f / 4}$ or 17 Adora2a ${ }^{\Delta L y z 2}$ macrophages and/or naive or septic B cells.

18 (I-K) Concentrations of IL-10 in the culture supernatants of naive, Adora2a ${ }^{\mathrm{t} / \mathrm{f}}$ or 19 Adora2a $^{\triangle L y z 2}$ macrophages with naive or septic Entpd1\%B cells in the presence 20 of CD39i, ATPyS, ADA and A2aRi $(100 \mu \mathrm{M})$.

21 (M) Representative flow cytometry dot plots and frequency of splenic IL-1022 EGFP+CD11 ${ }^{+}$cells 15 days after CLP. $\mathrm{n}=5-7$.

23 (N-P) Sepsis-surviving Adora2a ${ }^{f / f}$ and $A_{d o r a 2 a^{A} L y z 2}$ mice were challenged with $L$. 24 pneumophila 15 days after CLP, $\mathrm{n}=5-6$.

25 (N) Survival curves after L. pneumophila infection.

26 (O) Bacterial loads in the lungs after $L$. pneumophila infection.

27 (P) IL-10 concentrations in the lungs after $L$. pneumophila infection.

28 Data are representative of 2-3 independent experiments. ${ }^{*} p<0.05,{ }^{* *} p<0.01$, $29{ }^{* \star *} \mathrm{p}<0.001$. Mann-Whitney U test in B, D-H, O; two-tailed unpaired Student's t30 test in $\mathrm{C}, \mathrm{I}-\mathrm{M}, \mathrm{P}$; and Mantel-Cox log-rank test in $\mathrm{N}$. 
1 (A) Schematic representation detailing pharmacological inhibitors for the 2 metabolic pathways required for ATP generation.

3 (B-E) CD19+ $B$ cells were isolated from naive or sepsis-surviving mice and 4 cultured with IL-4 for $6 \mathrm{~h} \pm$ UK-5099 $(20 \mu \mathrm{M})$.

5 (B) Kinetic profile of extracellular acidification rate (ECAR) measured by 6 Seahorse under basal condition and in response to glucose, oligomycin, and 2$7 \quad D G$ at the indicated time points. $n=5$.

8 (C) Kinetic profile of oxygen consumption rate (OCR) measured by Seahorse, 9 under basal condition, and in response to oligomycin, FCCP, and rotenone at the 10 indicated time points. $n=6$.

11 (D) Maximal glycolysis calculated from ECAR profile. $n=5$.

12 (E) Basal respiration, ATP-linked, maximal respiration, and spare respiratory 13 capacity (SRC) calculated from OCR profile. $n=6$.

14 (F) Flow cytometry histogram and graph bar showing MFI for 2NBDG in $15 \mathrm{CD}^{2}{ }^{+} \mathrm{CD} 19^{+} \mathrm{B}$ cells. $\mathrm{n}=5$.

16 (G) mRNA expression of Hk1, Hk2, Hif1a in CD19+ $B$ cells determined by qPCR. $17 \mathrm{n}=8$.

18 (H) Intracellular ATP quantified in lysates of CD19+ $B$ cell stimulated with IL-4 in 19 the presence of 2-DG, 3PO, echinomycin, oligomycin, rotenone, UK-5099, 20 etomoxir or BPTES. $n=5$.

21 (I) Illustration showing the simplified representation of the ATP release via the 22 pannexin-1 channel and inhibition with carbenoxolone (CBX, $100 \mu \mathrm{M})$.

23 (J) Extracellular ATP quantified in the cell culture supernatant of $C D 19^{+} B$ cells 24 stimulated with IL-4 \pm CBX. $n=5$.

25 (K) Schematic representation of bacterial killing and IL-10 production analysis by 26 M $\varphi s$ co-cultured with naive or septic B cells in the presence of $L$. pneumophila \pm 27 CBX determined after 48h (B-L) (also see STAR Methods). Naive peritoneal 28 macrophages were pooled from 5 naive mice and $B$ cells were isolated from naïve 29 or CLP-surviving mice. $\mathrm{n}=6$.

30 (L) The number of viable bacteria recovered from cell lysates.

31 (M) IL-10 concentrations in cell culture supernatants.

32 Data are representative of one 2-3 independent experiments. ns, not significant. $33{ }^{*} \mathrm{p}<0.05,{ }^{* *} \mathrm{p}<0.01,{ }^{* * *} \mathrm{p}<0.001$ between indicated groups and $\# \mathrm{p}<0.05$ : 
1 compared to respective vehicle group. ns, not significant. One-way ANOVA with

2 Bonferroni posthoc tests in B, C, E; two-tailed unpaired Student's t-test in D, F-

$3 \mathrm{H}, \mathrm{J}, \mathrm{M}$; and Mann-Whitney $\mathrm{U}$ test in L.

4

5 FIGURE 7: Characterization of $\mathrm{CD} 39+\mathrm{B}$ cells in septic patients

6 (A) Representative flow cytometry plots and graph bar showing the frequency of

$7 \mathrm{Ki}^{+}{ }^{+} \mathrm{CD} 39^{+}$in $\mathrm{CD} 19^{+} \mathrm{B}$ cells from blood of septic patients $(\mathrm{n}=18)$ and healthy 8 controls $(n=16)$.

9 (B) Gating strategy for the identification of human blood B cell subsets. Naive B 10 cells $\left(\mathrm{CD}^{-} 8^{-} \mathrm{CD} 27^{-}\right)$, memory $\mathrm{B}$ cells $\left(\mathrm{CD} 38^{-} \mathrm{CD} 27^{+}\right)$, and plasmablasts $11\left(\mathrm{CD}_{38}{ }^{+} \mathrm{CD} 27^{+}\right)$gated in viable $\mathrm{CD} 19^{+} B$ cells from blood of septic patients $(n=21)$ 12 and healthy controls $(n=21)$.

13 (C) Representative flow cytometry plots of CD39 expression in B cell subsets from 14 septic patients $(n=21)$ and healthy controls $(n=21)$.

15 (D) Frequency of CD39 high (hi), intermediate (int), and negative (neg) 16 expression in plasmablast cells from septic patients $(n=21)$ and healthy controls 17 ( $\mathrm{n}=21)$.

18 (E) Ecto-ATPase activity of $C D 19^{+} B$ cells sorted from septic patients $(n=20)$ and 19 healthy controls $(n=21)$ cultured \pm CD39i.

20 (F) Plasma adenosine concentrations in septic patients $(n=21)$ and healthy 21 controls $(n=36)$.

22 (G) Plasma adenosine concentrations in patients with sepsis $(n=8)$ or septic 23 shock $(n=13)$ and healthy controls $(n=36)$.

24 (H) Correlation between Ecto-ATPase activity of CD19+ B cells and plasma 25 adenosine concentration for each septic patient $(n=20)$.

26 (I, J) $\mathrm{CD}_{14}{ }^{+}$monocytes $(\mathrm{M} \varphi)$ isolated from blood of a healthy donor were co27 cultured with septic or healthy $B$ cells in the presence of $L$. pneumophila 28 expressing luciferase at a $\mathrm{MOI}$ of 0.01 and $\mathrm{A} 2 \mathrm{aRi}$, apyrase or vehicle.

29 (I) Bacterial load determined by measuring the luminescence (RLU) on day 3 30 after culture.

31 (J) IL-10 concentration in the cell culture supernatants.

32 (K-L) Single-cell RNA-sequencing data of blood cells from individuals with sepsis 33 (Reyes et al., 2020). 
1 (K) UMAP reduction plot of $B$ cells from individuals with no sepsis (left) or patients 2 with sepsis (right). The cells in black represent the plasmablast cells according to 3 markers utilized by the original article.

4 (L) Relative frequency of plasmablast in patients with no sepsis (black) and with 5 sepsis (orange).

$6 \quad *, p<0.05$ : compared to vehicle healthy $B$ cell group. $\#, p<0.05$ : compared to 7 vehicle group of each individual. Two-tailed unpaired Student's t-test in A, F; one8 way ANOVA with Bonferroni posthoc tests in $\mathrm{D}, \mathrm{E}, \mathrm{G}, \mathrm{J} ; p$-value and correlation 9 coefficient ( $r$ ) were obtained using the nonparametric Spearman rank correlation 10 test in $\mathrm{H}$; and Mann-Whitney $\mathrm{U}$ test in $\mathrm{I}$. 
STAR METHODS

2

3 RESOURCE AVAILABILITY

4 Lead contact

5 Further information and requests for reagents may be obtained from the Lead

6 Contact, José Carlos Alves-Filho (jcafilho@usp.br).

8 Materials availability

9 This study did not generate new or unique reagents.

Data and code availability

12 This paper analyzes existing, publicly available data from (Reyes et al., 2020) at

13 Broad Institute Single Cell Portal (https://singlecell.broadinstitute.org/single cell):

14 SCP548 (subject PBMCs). These accession numbers for the datasets are listed 15 in the key resources table. All software and algorithms used in this study are 16 publicly available and listed in the Key Resource table. All original code has been 17 deposited and is publicly available at Zenodo 18 https://doi.org/10.5281/zenodo.4922037. DOls are listed in the key resources 19 table.

\section{EXPERIMENTAL MODEL AND SUBJECT DETAILS}

\section{Animals}

23 C57BL/6 wild-type and BALB/c wild-type mice were purchased from Charles 24 River. $\mu \mathrm{MT}^{-/-}$(002288), Adora2a ${ }^{-/}$(010685), Foxp3-DTR-EGFP (016958), /110 25 (002251), IL-10+/EGFP (014530), Lyz2 Cre (004781) and Rag 1/- (002216) mice were purchased from the Jackson Laboratory. Entpd1/- mice were generated as previously described (Enjyoji et al., 1999) and kindly provided by Dr. Gilles Kauffenstein. Adora2a $a^{\text {flox }}$ mice were generated as previously described (Cekic et al., 2013) and kindly provided by Dr. Joel Linden. Myeloid cell-(Adora2a $\left.{ }^{\Delta L z z}\right)$ specific-Adora2a-deficient mice were generated by crossing the Adora2a flox/flox mice with $L y z 2^{\text {Cre }}$ mice. $\mu \mathrm{MT}^{-/}$, Adora2a ${ }^{\text {flox }}$, Entpd1 ${ }^{--}$, Foxp3-DTR-EGFP, $1110^{-/}$, $\mathrm{IL}-10^{+/ E G F P}, L y z 2^{\text {Cre }}$, and Rag1\% mice used in this study were on a C57BL/6 background. Adora2a-- mice used in this study were on a BALB/c J background.

34 All mice were bred and maintained under specific pathogen-free conditions at the 
1 Animal Facility of the Ribeirão Preto Medical School, University of São Paulo. All

2 experiments were carried out with 7-9-week-old male mice according to the 3 guidelines of the Animal Welfare Committee of the Ribeirão Preto Medical

4 School, University of São Paulo (protocol number: 070/2012 and 251/2019).

\section{Patients}

7 Adult patients admitted to the Emergency Department of the School of Medicine

8 of Ribeirão Preto with sepsis or septic shock between October 2020 and

9 December 2020 were enrolled in the study (Table S1). Besides, age- and sexmatched healthy control volunteers were also included in the study. All patients enrolled fulfilled the criteria defined by the Third International Consensus Definitions for Sepsis and Septic Shock (Sepsis-3) (Singer et al., 2016). The exclusion criteria included active hematological malignancy or cancer and transplantation. Informed written consent from all participants was obtained. The study was approved by the Human Subjects Institutional Committee of the Ribeirão Preto Medical School, Brazil (Licence number: 30459114.6.0000.5440).

\section{Caecal ligation and puncture (CLP)-induced polymicrobial sepsis model}

CLP-induced polymicrobial sepsis model (Rittirsch et al., 2009): Mice were anesthetized by inhalation administration of isoflurane (1-3\%), and two punctures were made in the caecum with an 18- or 23-gauge needle to induce lethal or moderate CLP-induced sepsis, respectively. Sham mice were submitted to the same procedures without caecal puncture. All mice were given analgesic (12.5 mg. $\mathrm{kg}^{-1}$, tramadol, Agener União, subcutaneous) beginning $30 \mathrm{~min}$ before CLP and then every $12 \mathrm{~h}$ up to day 3 . To increase the survival rates after lethal sepsis (Nascimento et al., 2010), C57BL/6 background mice received an i.p. injection of ertapenem sodium (30 mg. $\mathrm{kg}^{-1}$, Merck) beginning six $\mathrm{h}$ after CLP and continuing every $12 \mathrm{~h}$ for the first three days. In experiments performed on BALB/C background, mice received antibiotics up to day 4 . In some experiments, septic mice were treated with $\mathrm{A} 2 \mathrm{aR}$ antagonist [8-(3-Chlorostyryl)-caffeine, $1 \mathrm{mg} \cdot \mathrm{kg}^{-1}$ in DMSO $5 \%$ in PBS], or CD39 inhibitor (ARL 67156 trisodium salt, $2 \mathrm{mg}^{\mathrm{kg}}{ }^{-1}$ in PBS). Mice were injected intraperitoneally with an A2aR antagonist or CD39 inhibitor $(200 \mu \mathrm{L})$ beginning on day three and continuing for 12 consecutive days (once a day). Survival was observed for up to 15 days. 
2 Microbial infection

3 Legionella pneumophila infection (Zamboni et al., 2006): L. pneumophila (F2111)

4 was kindly provided by Dr. Paul Edelstein (Edelstein et al., 2003). L. pneumophila

5 was grown on charcoal yeast extract agar (10 g.L $\mathrm{L}^{-1} 4$-morpholinepropanesulfonic

6 acid [MOPS], 10 g.L. ${ }^{-1}$ Yeast extract, pH6.9, 15 g.L ${ }^{-1}$ bacteriological agar, 2 g.L $\mathrm{L}^{-1}$

7 activated charcoal, supplemented with 0.4 g.L ${ }^{-1}$ L-cysteine and 0.135 g.L-1

$8 \mathrm{Fe}(\mathrm{NO} 3) 3)$ at $35-37^{\circ} \mathrm{C}$, for 4 days from frozen stocks. Single colonies were

9 streaked on fresh plates and allowed to grow for another 2 days. For in vivo

10 infections (Nascimento et al., 2010), mice were intranasally given a single dose

11 of $L$. pneumophila $\left(7 \times 10^{7}\right.$ bacteria in $\left.40 \mu \mathrm{L}\right)$.

12 Aspergillus fumigatus infection: $A$. fumigatus (strain CBS 144.89) was kindly

13 provided by Dr. Jean-Paul Latge (Beauvais et al., 1997). Conidia were grown on

1415 g.L ${ }^{-1}$ cristomalt-D diastase malt powder and 15 g.dL ${ }^{-1}$ bacteriological agar

15 slants at $35-37^{\circ} \mathrm{C}$ for $24 \mathrm{~h}$ and allowed to grow at room temperature for another

16 six days. For in vivo infections, mice were intratracheally given a single dose of

17 A. fumigatus $\left(5 \times 10^{7}\right.$ bacteria in $\left.50 \mu \mathrm{L}\right)$.

18 Survival was observed for up to 10 days.

\section{Cell purifications}

21 Primary mouse CD19+ $\mathrm{B}$ cells were purified from the spleen of mice using a 22 FACSAriall sorter (BD Biosciences). Cell purity was confirmed to be $\geq 95 \%$.

23 Peritoneal cells of mice were enriched for macrophages by adherence to 24 plastic Petri dishes for $16 \mathrm{~h}$. Peripheral blood mononuclear cells (PBMC) were 25 isolated from human peripheral blood using the ficoll-Paque Plus gradient (GE 26 Healthcare). Primary human CD19+ B cells were isolated by positive selection 27 from PBMCs using CD19 MACS beads Multisort (Miltenyi Biotec) according to 28 the manufacturer's recommendations. Cell purity was confirmed to be $\geq 95 \%$. 29 Primary human $\mathrm{CD}_{14}{ }^{+}$monocytes were purified by positive selection from 30 PBMCs using CD14 MACS beads Multisort (Miltenyi Biotec) according to the manufacturer's recommendations. Cell purity was confirmed to be $\geq 95 \%$. 
1 Two protocols were used. First, for reconstitution of Rag1-- mice (Guzik et al., 2 2007): B cells or vehicle (PBS) were injected i.v. into Rag ${ }^{-/-}$mice $\left(2 \times 10^{7}\right.$ 3 cells/mouse). The recipient mice were then submitted to CLP 3 weeks after 4 adoptive transfer. Second, to evaluate the role of septic B cells in the control of bacterial replication (Nascimento et al., 2017): B cells or vehicle (PBS) were injected i.v. into naïve WT mice $\left(5 \times 10^{6}\right.$ cells/mouse). The naïve recipient mice were then infected i.n. with $L$. pneumophila on day 7 after adoptive transfer.

\section{Generation of B cell chimeric mice}

10 For the generation of chimeric mice (Tsui et al., 2018), Entpd1 ${ }^{-/-}, \mu \mathrm{MT}^{--/}$, and C57BL/6 bone marrow cells were obtained by flushing the femur and tibia. C57BL/6 mice (12-weeks-old) were irradiated using a Cesium 137 source irradiator (Mark I model 25) at $7 \mathrm{~Gy}$. On the day after irradiation, the mice were divided into the following groups: (1) C57BL/6 mice repopulated with a mix of C57BL/6 BM cells and $\mu \mathrm{MT}^{-/-} \mathrm{BM}$ cells in proportion 1:4 (i.v.; $5 \times 10^{6} /$ mouse), called WT $\mu$ MT-chimera; (2) C57BL/6 mice repopulated with a mix of Entpd1 $1^{-/}$ $\mathrm{BM}$ cells and $\mu \mathrm{MT}^{-/-} \mathrm{BM}$ cells, called Entpd ${ }^{1-\alpha} \mu \mathrm{MT}$-chimera. After bone marrow transplantation, the mice were treated with the antibiotic Ciprofloxacin hydrochloride diluted in drinking water $\left(10 \mathrm{mg} \cdot \mathrm{mL}^{-1}, \mathrm{EMS}\right)$ for 15 days. After 2 months (period required for bone marrow engraftment), mice were submitted to CLP and were killed on day 15 after CLP.

\section{Bacterial replication on macrophage in co-culture with B cells}

For mouse samples: peritoneal macrophages from naïve mice were added to 48well plates at a density of $5 \times 10^{5}$ cells per well. Cells were infected by $0.1 \mathrm{MOI}$ L. pneumophila bacteria in the presence of B cells from the spleen of sepsissurviving or naive mice or medium alone. In some experiments, we added CD39i (ARL $67156200 \mu \mathrm{M}$, Tocris), Apyrase (20 U.mL ${ }^{-1}$, Sigma), ATPyS (100 $\mu \mathrm{M}$, Tocris), ADA (4 U.mL ${ }^{-1}$, Sigma), NECA (10 $\mu \mathrm{M}$, Tocris), A2aR antagonist (8-(3Chlorostyryl) caffeine, A2aRi, $100 \mu \mathrm{M}$, Sigma), A2B antagonist (selective inverse agonist, A2bRi, MRS 1706, $100 \mu \mathrm{M}$, Tocris), CBX (carbenoxolone disodium salt, $100 \mu \mathrm{M}$, Sigma) in the cultures. There were no antibiotics in the cell culture medium used for bacterial infection. On the second day, the supernatants were collected; cells were lysed with sterile $\mathrm{H}_{2} \mathrm{O}$ and plated for counted of counting of 
1 colony-forming units (CFU) after 4 days of incubation at $37^{\circ} \mathrm{C}$ (Nascimento et al., 2 2010). The results are expressed as log CFU per $\mathrm{mL}$.

3 For human samples: monocytes from the periphery blood of healthy volunteers

\section{METHODS DETAILS} were co-cultured with septic or healthy B cell in 96-well white plates at a density of $1 \times 10^{5}$ for each type of cells per well (triplicate). L. pneumophila strains (JR32) stably expressing the Photorhabdus luminescens luxCDABE operon was kindly provided by Dr. Dario Zamboni (Gonçalves et al., 2019). L. pneumophila was grown on charcoal yeast extract agar (10 g.L-1 4- orpholinepropanesulfonic acid [MOPS], 10 g.L $\mathrm{L}^{-1}$ Yeast extract, pH6.9, 15 g. $\mathrm{L}^{-1}$ bacteriological agar, $2 \mathrm{~g} . \mathrm{L}^{-1}$ activated charcoal, supplemented with $0.4 \mathrm{~g} . \mathrm{L}^{-1} \mathrm{~L}$-cysteine and $0.135 \mathrm{~g} . \mathrm{L}^{-1}$ $\mathrm{Fe}(\mathrm{NO} 3) 3$ ) at $35-37^{\circ} \mathrm{C}$, for 4 days from frozen stocks. Single colonies were streaked on fresh plates and allowed to grow for another 2 days. Cells were infected by $L$. pneumophila bacteria expressing luciferase at an $\mathrm{MOI}$ of 0.01 in the presence of A2aRi (8-(3-Chlorostyryl) caffeine, $100 \mu \mathrm{M}$, Sigma) or Apyrase (20 U. $\mathrm{mL}^{-1}$, Sigma). There were no antibiotics in the cell culture medium used for bacterial infection. On the third day, luminescence emission was measured at $470 \mathrm{~nm}$ with a Spectra-L plate reader (Molecular Devices, California, USA), and the supernatants were collected. The results are expressed as live bacteria (RLU).

\section{Adenosine quantification}

Blood collection and sample preparation. For adenosine quantification in plasma (Veras et al., 2015), blood was collected in tubes containing $10 \mu \mathrm{M}$ of pentostatin (adenosine deaminase inhibitor, Tocris) and heparin (for mouse) or $\mathrm{K}_{3}$ EDTA (for human). Blood samples were centrifuged at $10,000 \times g$ for 10 min at $4{ }^{\circ} \mathrm{C}$, and plasma was stored at $-80^{\circ} \mathrm{C}$ until the analyses. For adenosine quantification in the plasma, theophylline (internal standard) and $1 \mathrm{~mL}$ of acetonitrile were added in $200 \mu \mathrm{L}$ of plasma. The tube was vortexed for $2 \mathrm{~min}$, centrifuged at $10,000 \times \mathrm{g}$ for $10 \mathrm{~min}$ at $4{ }^{\circ} \mathrm{C}$, and the supernatants were evaporated by a vacuum concentrator system (CentriVap, Labcongo Corporation). The dry residue was resuspended in $100 \mu \mathrm{L}$ of mobile phase (water with $0.1 \%$ formic acid). A similar protocol was used to adenosine the curve. The different concentrations of 
1 adenosine (Sigma) were added to the plasma (collected without adenosine 2 deaminase inhibitor) together with theophylline (internal standard). Samples 3 (100 $\mu \mathrm{L})$ were analyzed by LC-MS/MS using a previously described method 4 (Veras et al., 2015).

5 For adenosine detection in the supernatant, B cells from sepsis-surviving mice

LC-MS/MS equipment and conditions. For adenosine quantification in plasma, were stimulated with ATP ( $100 \mu \mathrm{M}$, Sigma) by $15 \mathrm{~min}$. At the end of the cultures, the supernatants were precipitated with $66 \%$ acetonitrile (J. T. Baker) to denature protein stabilize adenosine and diluted $33 \%$ in water for adenosine analysis. Different concentrations of adenosine (Sigma) were prepared in methanol to construct a standard curve. the analyses were carried out by LC-MS/MS (liquid chromatography-mass spectrometry). Chromatographic analyzes were performed using highperformance liquid chromatography equipment (Shimadzu, Kyoto, Japan), consisted of an LC-10ADVP binary solvent delivery pumps, SLC-10AVP system controller, SIL-20A Prominence autosampler, and CTO-10ASVP column oven set at $25^{\circ} \mathrm{C}$. The separations were performed using a $100 \times 3.9 \mathrm{~mm}$ XTerra MS C18 column with a particle size of $3.5 \mu \mathrm{m}$ (Waters, Milford, MA, USA) and a $20 \times 3.9 \mathrm{~mm}$ XTerra MS C18 guard column with a particle size of $5 \mu \mathrm{m}$ (Waters, Milford, MA, USA). The mobile phase was composed of $(X)$ water with $0.1 \%$ formic acid and $(Y)$ acetonitrile. The binary gradient elution ( $X$ : $Y$ proportion, $v / v)$, at a flow rate of $0.3 \mathrm{~mL}$. $\mathrm{min}^{-1}$, was composed by $96: 4$ from 0 to $5 \mathrm{~min}$; switching to $50: 50$ from 5 to $7 \mathrm{~min}$; maintained by $11 \mathrm{~min}$; switching back to the initial condition from 11 to $13 \mathrm{~min}$, and maintaining on this proportion till $16 \mathrm{~min}$. This system was coupled to a mass spectrometer composed of mass analyzers of the triple-quadrupole type (Quattro LC, Micromass, Manchester, UK) with an electrospray interface, operating in positive mode $(E S I+)$. The temperatures of the source block were set at $100{ }^{\circ} \mathrm{C}$, and desolvation gas was set at $350{ }^{\circ} \mathrm{C}$. Argon was used as collision gas, and nitrogen was used as both desolvation

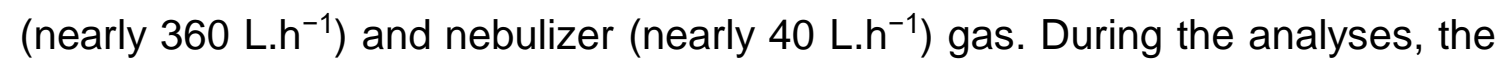
voltages employed in the ESI source were $3 \mathrm{kV}$ for the capillary, $3 \mathrm{~V}$ for the extractor, and $20 \mathrm{~V}$ for the cone. The ions detection was carried out in the multiple reaction monitoring (MRM) mode, employing collision energy of $15 \mathrm{eV}$, monitoring 
1 the transitions of the $\mathrm{m} / \mathrm{z} 268$ precursor ion to the $\mathrm{m} / \mathrm{z} 136$ production for 2 adenosine $(268>136)$ and $181>124$ for theophylline (internal standard). The 3 analytical data were calculated using the MassLynx software (Micromass, 4 Manchester, UK).

5 For adenosine detection in the supernatant, samples or standards $(100 \mu \mathrm{L})$ were 6 injected in a Xevo TQ-S system Waters Acquity UPLC HSS with column C18 7 Acuity UPLC HSS with 1,0×150 mm (liquid chromatography separation). The

8 temperature of the column oven was set at $40^{\circ} \mathrm{C}$. The solvent system consisted 9 of $0.1 \%$ acetic acid in water and $0.1 \%$ acetic acid in methanol. The flow rate was

\section{Flow cytometry}

Flow cytometric staining was performed as previously described (Nascimento et al., 2017). For mouse staining, Foxp3 EGFP, $\mu \mathrm{MT}^{-/-}$, WT cells were stained with Live/Dead viability dye (Thermo Fisher Scientific) and specific antibodies to CD39 (24DMS1 and Duha59, Thermo Fisher Scientific and BioLegend), CD19 (1D3, Thermo Fisher Scientific or BD Biosciences; 6D5, BioLegend), CD11b (M1/70, Thermo Fisher Scientific), CD11c (N418, BioLegend), CD4 (RM4-5, BioLegend), B220 (CD45R; RA3-6B2, BioLegend or BD Bioscience), CD8 (YTS156.7.7, BioLegend), TCR $\beta$ (H57-597, Thermo Fisher Scientific), NK1.1 (PK136, BioLegend), Ly6G (1A8, BD Biosciences), CD223 (LAG-3, C9B7W, Biolegend), IgM (RMM-1, BioLegend), IgD (11-26c.2a, BD Biosciences), CD138 (281-2, BioLegend), CD3 (17A2, Thermo Fisher Scientific), CD5 (53-7.3, BD 34 Biosciences), CD23 (B3B4, Thermo Fisher Scientific), CD21/CD35 (CR2/CR1; 
1 7E9, BioLegend), Ki67 (B56, BD Biosciences), and CD45 (30-F11, BioLegend)

2 for $30 \mathrm{~min}$. For human cells stanning, PBMC were stained with Live/Dead viability

3 dye (Thermo Fisher Scientific) and specific antibodies to CD39 (TU66, BD

4 Biosciences), CD19 (HIB19, BD Biosciences), CD38 (HIT2, BD Biosciences),

5 CD27 (M-T271, BD Biosciences), Ki67 (20Raj1, Thermo Fisher Scientific) for 30

6 min. For 2-NBDG uptake detection (Thermo Fisher Scientific), the reaction was

7 stopped by removing the incubation medium and washing the cells twice with

8 PBS. Cells were subsequently stained with Live/Dead viability dye (Thermo

9 Fisher Scientific)and specific antibodies to CD39 and CD19 for 10 min, and flow

10 cytometry analysis was performed within $30 \mathrm{~min}$. For IL-10 detection, IL-10 EGFP

11 cells were incubated with phorbol-12-myristate-13-acetate $\left(50 \mathrm{ng} \cdot \mathrm{mL}^{-1}\right.$, Sigma-

12 Aldrich), ionomycin (500 ng. $\mathrm{mL}^{-1}$, Sigma-Aldrich), and GolgiStop (BD

13 Biosciences) for $4 \mathrm{~h}$ prior to antibody staining. Fresh cells were collected on

14 Canto, Verse, and Fortessa flow cytometers (BD Biosciences) and analyzed 15 using FlowJo (TreeStar) software. Cells were sorted using a FACS Aria II.

\section{High-dimensional flow cytometric analyses}

High-dimensional flow cytometric analysis of the CD39+ expression on the cell populations from the spleen of naïve and sepsis-surviving mice were performed in immune cells based on the following gate strategies, on the live CD $45^{+}$cells: neutrophils $\left(\mathrm{Ly}_{6 \mathrm{G}}{ }^{+} \mathrm{CD} 11 \mathrm{~b}^{+}\right), M \varphi \quad\left(\mathrm{F} 4 / 80^{+} \mathrm{CD} 11 \mathrm{~b}^{+}\right), \mathrm{DCs} \quad\left(\mathrm{CD} 11 \mathrm{C}^{+} \mathrm{CD} 11 \mathrm{~b}^{+}\right)$, $\mathrm{CD}^{+}{ }^{+}$Foxp3 ${ }^{-} \mathrm{T}$ cells $\left(\mathrm{Foxp}^{-} \mathrm{CD} 4^{+} \mathrm{TCR}^{+}\right), \mathrm{CD}^{+} \mathrm{T}$ cells $\left(\mathrm{CD} 8^{+} \mathrm{TCR} \beta^{+}\right)$, $\mathrm{CD}^{+}{ }^{+} \mathrm{Foxp}^{+}{ }^{+}$Treg cells $\left(\mathrm{Foxp}^{+} \mathrm{CD} 4^{+} \mathrm{TCR} \beta^{+}\right)$, B cells $\left(\mathrm{CD} 19^{+} \mathrm{B} 220^{\text {var }}\right)$, NK cells $\left(\mathrm{NK} 1.1^{+}\right)$and NKT cells $\left(\mathrm{NK} 1.1^{+} \mathrm{TCR} \beta^{+}\right)$. The t-SNE algorithm was performed for unsupervised analysis of the entire flow cytometry dataset (10 samples per experiment) generated from naïve and sepsis-surviving mice. The t-SNE algorithm was run on the DownSample of live CD45 ${ }^{+}$CD39+ populations $[100,000$ cells, randomly selected from naïve $(n=5)$ and sepsis survivors $(n=5), 50,000$ cells each group)]. Flow cytometry-based immune cell populations were overlaid as a color dimension. For the B cells subpopulation analysis, cells were gated on the live $\mathrm{CD}^{+} 5^{+}$as follows: total B cells (CD19+ CD3 $\left.{ }^{\text {neg }}\right)$, CD39 subset $\left(C D 39^{+}\right)$, $\lg \mathrm{D}+$ subset $\left(\lg \mathrm{D}^{+} \lg \mathrm{M}^{\mathrm{neg}}\right), \lg \mathrm{D}+\lg \mathrm{M}+$ subset $\left(\lg \mathrm{D}^{+} \lg \mathrm{M}^{+}\right)$, $\lg D$ neg $\lg M n e g$ subset $\left(\lg D^{\text {neg }} \lg \mathrm{M}^{\text {neg }}\right)$, and $\mathrm{CD138}+$ subset $\left(\mathrm{CD} 138^{+}\right)$. $\mathrm{t}-\mathrm{SNE}$ was run on the DownSample of 150,000 live $C D 39^{+} \mathrm{CD} 19^{+}$cells randomly sampled from the 
1 spleen of naïve and sepsis-surviving mice ( $n=5$ per group and 75,000 cells from

2 each group). Gating strategies for flow cytometry analysis are shown in Figures

3 S3A and S3E.

4

5 Ecto-ATPase activity

6 The ecto-ATPase activity was determined by the malachite green assay, with 7 some modifications as described (Peres et al., 2015). Splenic or B cells ( $2 \times 10^{5}$

8 cells/well for mouse cells and $1 \times 10^{5}$ cells/well for human cells) were pre-treated 9 with CD39i (ARL 67156 trisodium salt, $200 \mu \mathrm{M}$, Tocris) or vehicle for $30 \mathrm{~min}$ and 10 then stimulated with $1 \mathrm{mM} \mathrm{ATP} \mathrm{(Sigma)} \mathrm{in} \mathrm{a} 96$-well plate at $37^{\circ} \mathrm{C}$ for $30 \mathrm{~min}$. 11 The supernatant cell culture medium was collected, and the malachite green 12 solution was added (one-part $4.2 \mathrm{~g}$ ammonium molybdate dissolved in $100 \mathrm{~mL} 4$ $13 \mathrm{M} \mathrm{HCl}+$ three parts $0.045 \%$ malachite green in $\mathrm{H}_{2} \mathrm{O}$ ). Next, optical density was 14 measured at $650 \mathrm{~nm}$. The levels of inorganic phosphate released were calculated 15 from a parallel prepared phosphate standard curve $\left(\mathrm{K}_{2} \mathrm{HPO}_{4}\right)$.

qPCR

Total RNA from CD19+ B cells from the spleen was extracted using an RNeasy Mini Kit (74106, Qiagen), according to the manufacturer's directions. First-strand cDNA was synthesized from $500 \mu \mathrm{g}$ of RNA using the high-capacity cDNA Reverse Transcription Kit (4368814, Thermo Fisher Scientific). Quantitative realtime PCR was performed using Power Syber Green PCR Master Mix TaqMan (Thermo Fisher Scientific), primers as described in the Key Resources Table and, the Viia7 Real-Time PCR system. The data were normalized to Gapdh values, and the fold change was analyzed using the DDCt method. The relative gene expression was expressed in arbitrary units based on the naive group, which was assigned a value of 1 .

\section{ELISA}

$30 \quad \mathrm{IL}-10$ concentration in culture supernatants and lung tissues was determined by 
1 Intracellular or extracellular ATP was detected using the ATPlite Luminescence

2 ATP Detection Assay (PerkinElmer, Waltham, MA), according to the 3 manufacturer's protocol. For the detection of intracellular ATP, CD19+ $B$ cells were stimulated with IL-4 $\left(10 \mathrm{ng} \cdot \mathrm{mL}^{-1}\right)$ at $37^{\circ} \mathrm{C}$ with $5 \% \mathrm{CO}_{2}$ for $6 \mathrm{~h}$ in the presence obligatory of a pannexin-1 channel inhibitor (carbenoxolone disodium salt, 100 $\mu \mathrm{M}$, Sigma), and/or with 2-DG $(3 \mathrm{mM}), 3 P O(30 \mu \mathrm{M})$, echinomycin $(5 \mathrm{nM})$, oligomycin $(1 \mu \mathrm{M})$, rotenone $(2.5 \mu \mathrm{M})$, UK-5099 $(20 \mu \mathrm{M})$, etomoxir $(3 \mu \mathrm{M})$ or BPTES $(10 \mu \mathrm{M})$. The cells were lysed to measure ATP levels $6 \mathrm{~h}$ later. For the detection of the extracellular ATP, we performed CD19+ $B$ cell culture stimulated with IL-4 (10 ng. $\mathrm{mL}^{-1}$ ) for $6 \mathrm{~h}$ in the presence of a CD39 inhibitor (ARL 67156 trisodium salt, $200 \mu \mathrm{M}$, Tocris), and culture supernatants were collected and measured for ATP levels $6 \mathrm{~h}$ later. In some experiments, B cells were incubated with $\mathrm{CBX}$ (carbenoxolone disodium salt, $100 \mu \mathrm{M}$, Sigma) for measured released ATP.

\section{Glucose uptake assay}

Glucose uptake was detected using fluorescent 2-NBDG (Cayman) according to the manufacturer's protocol. B cells were plated at $1 \times 10^{6} /$ well in 12 -well plates and, after $18 \mathrm{~h}$ pre-incubation, all culture medium was removed from each well and replaced with $100 \mu \mathrm{L}$ of culture medium without glucose in the presence of fluorescent 2-NBDG $(30 \mu \mathrm{M})$ compounds. Plates were incubated at $37^{\circ} \mathrm{C}$ with 5 $\% \mathrm{CO}_{2}$ for $30 \mathrm{~min}$. The reaction was stopped by removing the incubation medium and washing the cells twice with PBS.

\section{Metabolic Profiling}

26 Extracellular acidification rate (ECAR) and oxygen consumption rate (OCR) were measured using the Seahorse XF96 Analyzer (Agilent Technologies) according to the manufacturer's guidelines (Agilent Seahorse XF24). Isolated CD19+B cells were stimulated with IL-4 $\left(10 \mathrm{ng} \cdot \mathrm{mL}^{-1}\right)$ at $37^{\circ} \mathrm{C}$ with $5 \% \mathrm{CO}_{2}$ for $6 \mathrm{~h}$. Before analysis, $4 \times 10^{5} \mathrm{~B}$ cells were washed with XF media (for ECAR: non-buffered RPMI 1640 containing $2 \mathrm{mM} \mathrm{L-glutamine} \mathrm{and} 1 \mathrm{mM}$ sodium pyruvate; for OCR non-buffered RPMI 1640 containing $1 \mathrm{mM}$ glucose and $1 \mathrm{mM}$ sodium pyruvate) 
1 and incubated for $30 \mathrm{~min}$ at $37^{\circ} \mathrm{C}$ in the absence of $\mathrm{CO}_{2}$. ECAR was measured 2 under basal conditions and, after the addition of the following drugs: $10 \mathrm{mM}$ 3 glucose, $1 \mu \mathrm{M}$ oligomycin, $50 \mathrm{mM}$ 2DG (XF Glycolysis Stress test Kit, Agilent 4 Technologies). OCR was measured under basal conditions and, after the addition 5 of the following drugs: $1.5 \mu \mathrm{M}$ Oligomycin, $1 \mu \mathrm{M}$ FCCP, $5 \mu \mathrm{M}$ Rotenone (XF Mito 6 Stress test Kit, Agilent Technologies).

\section{Re-analyzing Public Datasets}

9 We re-analyzed single-cell transcriptomic data from the peripheral blood 10 mononuclear cells (PBMC) of septic patients from a public dataset (Reyes et al., 2020). Basically, the samples were combined into two major groups for further comparisons, septic patients (sepsis) and non-septic patients (no sepsis). The sepsis group included samples from patients with urosepsis and patients with sepsis admitted to the medical intensive care unit, whereas the no sepsis group included samples from healthy patients and patients without sepsis admitted to the medical intensive care unit. B cells were filtered based on the authors' previous annotation for downstream analysis (Reyes et al., 2020). Specifically, the data matrices of 7970 B cells were imported to Seurat v3.1 (Stuart et al., 2019) by filtering genes expressed in at least 10 cells and more than 100 unique molecular identifiers (UMI) counts per cell. For the pre-processing step, outlier cells were filtered out based on three metrics (library size $<10000$, number of expressed genes between 200 and 2000, and mitochondrial percentage expression < 5), resulting in a matrix with 13077 genes and 5104 cells. The remaining counts were normalized using the 'LogNormalize' method with a scale factor of 10000 . The top 2,000 variable genes were then identified using the 'vst' method using the FindVariableFeatures function. Percent of mitochondrial genes was regressed out in the scaling step, and Principal Component Analysis (PCA) was performed using the top 2,000 variable genes with 50 dimensions. Additionally, a clustering analysis was performed on the first 7 principal components using a resolution of 0.6 followed by Uniform Manifold Approximation and Projection (UMAP), a dimensionality reduction technique for data visualization. Then, differential gene expression analysis was performed using FindAllMarkers function with default parameters to obtain a list of significant 
1 gene markers for each cluster of cells. The plasmablast cells were identified by

2 expression of CD39 gene counts $>0$ in the RNA assay and BS3 plasmablast 3 gene markers previously described by Reyes et al. 2020. Relative abundance of

4 plasmablast in patients with no sepsis and with sepsis was calculated by dividing 5 the number of plasmablasts in each group by the total number of plasmablasts.

6 For enrichment analyses, we utilized the EnrichR tool (Chen et al., 2013) with

7 Reactome 2016 database using plasmablast gene markers as input list.

9 QUANTIFICATION AND STATISTICAL ANALYSIS

10 Prism 8 software (GraphPad) was used for data analysis. We observed normal 11 distribution. Survival studies were analyzed with the Mantel-Cox log-rank test, 12 and microbial counts were calculated using the Mann-Whitney $U$ test. 13 Comparisons for two groups were calculated using unpaired two-tailed Student's 14 t-tests and multiple comparisons by one-way ANOVA with Bonferroni's posthoc 15 tests. Comparisons for the time course of CLP groups with a control group were 16 performed using one-way ANOVA results with Dunnett posthoc tests. 17 Correlations were analyzed with two-tailed nonparametric Spearman rank correlation tests. Differential gene expression analysis was performed using the 19 FindAllMarkers function using the Mann-Whitney $U$ test to obtain a list of 20 significant gene markers for each cluster of cells with default parameters. Data 21 are represented as means \pm SEM or bacterial load as a median. Statistical 22 significance: ${ }^{*} p<0.05 ;{ }^{* *} p<0.01 ;{ }^{* *} p<0.001$. 


\section{REFERENCE}

Allard, B., Longhi, M.S., Robson, S.C., and Stagg, J. (2017). The ectonucleotidases CD39 and CD73: Novel checkpoint inhibitor targets. Immunol Rev 276, 121-144. 10.1111/imr.12528.

Antonioli, L., Pacher, P., Vizi, E.S., and Haskó, G. (2013). CD39 and CD73 in immunity and inflammation. Trends Mol Med 19, 355-367. 10.1016/j.molmed.2013.03.005.

Beauvais, A., Monod, M., Debeaupuis, J.P., Diaquin, M., Kobayashi, H., and Latgé, J.P. (1997). Biochemical and antigenic characterization of a new dipeptidyl-peptidase isolated from Aspergillus fumigatus. J Biol Chem 272, 6238-6244. 10.1074/jbc.272.10.6238.

Behnsen, J., Hartmann, A., Schmaler, J., Gehrke, A., Brakhage, A.A., and Zipfel, P.F. (2008). The opportunistic human pathogenic fungus Aspergillus fumigatus evades the host complement system. Infect Immun 76, 820-827. 10.1128/IAI.01037-07.

Benjamim, C.F., Hogaboam, C.M., Lukacs, N.W., and Kunkel, S.L. (2003). Septic mice are susceptible to pulmonary aspergillosis. Am J Pathol 163, 2605-2617. 10.1016/S00029440(10)63615-2.

Berjeaud, J.M., Chevalier, S., Schlusselhuber, M., Portier, E., Loiseau, C., Aucher, W., Lesouhaitier, O., and Verdon, J. (2016). Legionella pneumophila: The Paradox of a Highly Sensitive Opportunistic Waterborne Pathogen Able to Persist in the Environment. Front Microbiol 7, 486. 10.3389/fmicb.2016.00486.

Boomer, J.S., To, K., Chang, K.C., Takasu, O., Osborne, D.F., Walton, A.H., Bricker, T.L., Jarman, S.D., Kreisel, D., Krupnick, A.S., et al. (2011). Immunosuppression in patients who die of sepsis and multiple organ failure. JAMA 306, 2594-2605. 10.1001/jama.2011.1829.

Borsellino, G., Kleinewietfeld, M., Di Mitri, D., Sternjak, A., Diamantini, A., Giometto, R., Höpner, S., Centonze, D., Bernardi, G., Dell'Acqua, M.L., et al. (2007). Expression of ectonucleotidase CD39 by Foxp3+ Treg cells: hydrolysis of extracellular ATP and immune suppression. Blood 110, 1225-1232. 10.1182/blood-2006-12-064527.

Caro-Maldonado, A., Wang, R., Nichols, A.G., Kuraoka, M., Milasta, S., Sun, L.D., Gavin, A.L., Abel, E.D., Kelsoe, G., Green, D.R., and Rathmell, J.C. (2014). Metabolic reprogramming is required for antibody production that is suppressed in anergic but exaggerated in chronically BAFF-exposed B cells. J Immunol 192, 3626-3636. 10.4049/jimmunol.1302062.

Cekic, C., Sag, D., Day, Y.J., and Linden, J. (2013). Extracellular adenosine regulates naive T cell development and peripheral maintenance. J Exp Med 210, 2693-2706. 10.1084/jem.20130249. Chen, E.Y., Tan, C.M., Kou, Y., Duan, Q., Wang, Z., Meirelles, G.V., Clark, N.R., and Ma'ayan, A. (2013). Enrichr: interactive and collaborative HTML5 gene list enrichment analysis tool. BMC Bioinformatics 14, 128. 10.1186/1471-2105-14-128.

Colgan, S.P., Eltzschig, H.K., Eckle, T., and Thompson, L.F. (2006). Physiological roles for ecto-5'nucleotidase (CD73). Purinergic Signal 2, 351-360. 10.1007/s11302-005-5302-5.

Couper, K.N., Blount, D.G., and Riley, E.M. (2008). IL-10: the master regulator of immunity to infection. J Immunol 180, 5771-5777. 10.4049/jimmunol.180.9.5771.

Culton, D.A., O'Conner, B.P., Conway, K.L., Diz, R., Rutan, J., Vilen, B.J., and Clarke, S.H. (2006). Early preplasma cells define a tolerance checkpoint for autoreactive B cells. J Immunol 176, 790802. 10.4049/jimmunol.176.2.790.

Deaglio, S., Dwyer, K.M., Gao, W., Friedman, D., Usheva, A., Erat, A., Chen, J.F., Enjyoji, K., Linden, J., Oukka, M., et al. (2007). Adenosine generation catalyzed by CD39 and CD73 expressed on regulatory $T$ cells mediates immune suppression. J Exp Med 204, 1257-1265. 10.1084/jem.20062512.

Dwyer, K.M., Deaglio, S., Gao, W., Friedman, D., Strom, T.B., and Robson, S.C. (2007). CD39 and control of cellular immune responses. Purinergic Signal 3, 171-180. 10.1007/s11302-006-9050y.

Edelstein, P.H., Weiss, W.J., and Edelstein, M.A. (2003). Activities of tigecycline (GAR-936) against Legionella pneumophila in vitro and in guinea pigs with L. pneumophila pneumonia. Antimicrob Agents Chemother 47, 533-540. 10.1128/aac.47.2.533-540.2003. 
Enjyoji, K., Sévigny, J., Lin, Y., Frenette, P.S., Christie, P.D., Esch, J.S., Imai, M., Edelberg, J.M., Rayburn, H., Lech, M., et al. (1999). Targeted disruption of cd39/ATP diphosphohydrolase results in disordered hemostasis and thromboregulation. Nat Med 5, 1010-1017. 10.1038/12447.

Figueiró, F., Muller, L., Funk, S., Jackson, E.K., Battastini, A.M., and Whiteside, T.L. (2016). Phenotypic and functional characteristics of CD39. Oncoimmunology 5, e1082703. 10.1080/2162402X.2015.1082703.

Fredholm, B.B., IJzerman, A.P., Jacobson, K.A., Klotz, K.N., and Linden, J. (2001). International Union of Pharmacology. XXV. Nomenclature and classification of adenosine receptors. Pharmacol Rev 53, 527-552.

10 Gerdes, J., Lemke, H., Baisch, H., Wacker, H.H., Schwab, U., and Stein, H. (1984). Cell cycle 11 analysis of a cell proliferation-associated human nuclear antigen defined by the monoclonal 12 antibody Ki-67. J Immunol 133, 1710-1715.

13 Gonçalves, A.V., Margolis, S.R., Quirino, G.F.S., Mascarenhas, D.P.A., Rauch, I., Nichols, R.D., 14 Ansaldo, E., Fontana, M.F., Vance, R.E., and Zamboni, D.S. (2019). Gasdermin-D and Caspase-7

are the key Caspase-1/8 substrates downstream of the NAIP5/NLRC4 inflammasome required for restriction of Legionella pneumophila. PLoS Pathog 15, e1007886. 10.1371/journal.ppat.1007886.

Guzik, T.J., Hoch, N.E., Brown, K.A., McCann, L.A., Rahman, A., Dikalov, S., Goronzy, J., Weyand, C., and Harrison, D.G. (2007). Role of the $T$ cell in the genesis of angiotensin II induced hypertension and vascular dysfunction. J Exp Med 204, 2449-2460. 10.1084/jem.20070657.

Hasko, G., Linden, J., Cronstein, B., and Pacher, P. (2008). Adenosine receptors: therapeutic aspects for inflammatory and immune diseases. Nat Rev Drug Discov 7, 759-770. $10.1038 / \mathrm{nrd} 2638$.

Haskó, G., and Cronstein, B. (2013). Regulation of inflammation by adenosine. Front Immunol 4, 85. 10.3389/fimmu.2013.00085.

Haskó, G., and Pacher, P. (2012). Regulation of macrophage function by adenosine. Arterioscler Thromb Vasc Biol 32, 865-869. 10.1161/ATVBAHA.111.226852.

Jabs, C.M., Sigurdsson, G.H., and Neglen, P. (1998). Plasma levels of high-energy compounds compared with severity of illness in critically ill patients in the intensive care unit. Surgery 124 , 65-72. S0039606098001950 [pii].

Jacobson, K.A., Nikodijević, O., Padgett, W.L., Gallo-Rodriguez, C., Maillard, M., and Daly, J.W. (1993). 8-(3-Chlorostyryl)caffeine (CSC) is a selective A2-adenosine antagonist in vitro and in vivo. FEBS Lett 323, 141-144. 10.1016/0014-5793(93)81466-d.

Kaku, H., Cheng, K.F., Al-Abed, Y., and Rothstein, T.L. (2014). A novel mechanism of B cellmediated immune suppression through CD73 expression and adenosine production. J Immunol 193, 5904-5913. 10.4049/jimmunol.1400336.

Lévesque, S.A., Lavoie, E.G., Lecka, J., Bigonnesse, F., and Sévigny, J. (2007). Specificity of the ecto-ATPase inhibitor ARL 67156 on human and mouse ectonucleotidases. Br J Pharmacol 152, 141-150. 10.1038/sj.bjp.0707361.

Maliszewski, C.R., Delespesse, G.J., Schoenborn, M.A., Armitage, R.J., Fanslow, W.C., Nakajima, T., Baker, E., Sutherland, G.R., Poindexter, K., and Birks, C. (1994). The CD39 lymphoid cell activation antigen. Molecular cloning and structural characterization. J Immunol 153, 35743583.

Martin, C., Leone, M., Viviand, X., Ayem, M.L., and Guieu, R. (2000). High adenosine plasma concentration as a prognostic index for outcome in patients with septic shock. Crit Care Med 28, 3198-3202.

Mempin, R., Tran, H., Chen, C., Gong, H., Kim Ho, K., and Lu, S. (2013). Release of extracellular ATP by bacteria during growth. BMC Microbiol 13, 301. 10.1186/1471-2180-13-301.

Nascimento, D.C., Alves-Filho, J.C., Sônego, F., Fukada, S.Y., Pereira, M.S., Benjamim, C., Zamboni, D.S., Silva, J.S., and Cunha, F.Q. (2010). Role of regulatory T cells in long-term immune dysfunction associated with severe sepsis. Crit Care Med 38, 1718-1725. 10.1097/CCM.0b013e3181e78ad0. 
Nascimento, D.C., Melo, P.H., Piñeros, A.R., Ferreira, R.G., Colón, D.F., Donate, P.B., Castanheira, F.V., Gozzi, A., Czaikoski, P.G., Niedbala, W., et al. (2017). IL-33 contributes to sepsis-induced long-term immunosuppression by expanding the regulatory $T$ cell population. Nat Commun 8 , 14919. 10.1038/ncomms14919.

Otto, G.P., Sossdorf, M., Claus, R.A., Rödel, J., Menge, K., Reinhart, K., Bauer, M., and Riedemann, N.C. (2011). The late phase of sepsis is characterized by an increased microbiological burden and death rate. Crit Care 15, R183. 10.1186/cc10332.

Peres, R.S., Liew, F.Y., Talbot, J., Carregaro, V., Oliveira, R.D., Almeida, S.L., França, R.F., Donate, P.B., Pinto, L.G., Ferreira, F.I., et al. (2015). Low expression of CD39 on regulatory T cells as a biomarker for resistance to methotrexate therapy in rheumatoid arthritis. Proc Natl Acad Sci U S A 112, 2509-2514. 10.1073/pnas.1424792112.

Prescott, H.C., and Angus, D.C. (2018). Enhancing Recovery From Sepsis: A Review. JAMA 319, 62-75. 10.1001/jama.2017.17687.

Ramakers, B.P., Riksen, N.P., van den Broek, P., Franke, B., Peters, W.H., van der Hoeven, J.G., Smits, P., and Pickkers, P. (2011). Circulating adenosine increases during human experimental endotoxemia but blockade of its receptor does not influence the immune response and subsequent organ injury. Crit Care 15, R3. 10.1186/cc9400.

Reyes, M., Filbin, M.R., Bhattacharyya, R.P., Billman, K., Eisenhaure, T., Hung, D.T., Levy, B.D., Baron, R.M., Blainey, P.C., Goldberg, M.B., and Hacohen, N. (2020). An immune-cell signature of bacterial sepsis. Nat Med 26, 333-340. 10.1038/s41591-020-0752-4.

Rittirsch, D., Huber-Lang, M.S., Flierl, M.A., and Ward, P.A. (2009). Immunodesign of experimental sepsis by cecal ligation and puncture. Nat Protoc 4, 31-36. 10.1038/nprot.2008.214.

Robson, S.C., Sévigny, J., and Zimmermann, H. (2006). The E-NTPDase family of ectonucleotidases: Structure function relationships and pathophysiological significance. Purinergic Signal 2, 409-430. 10.1007/s11302-006-9003-5.

Rosser, E.C., and Mauri, C. (2015). Regulatory B cells: origin, phenotype, and function. Immunity 42, 607-612. 10.1016/j.immuni.2015.04.005.

Rosser, E.C., Piper, C.J.M., Matei, D.E., Blair, P.A., Rendeiro, A.F., Orford, M., Alber, D.G., Krausgruber, T., Catalan, D., Klein, N., et al. (2020). Microbiota-Derived Metabolites Suppress Arthritis by Amplifying Aryl-Hydrocarbon Receptor Activation in Regulatory B Cells. Cell Metab 31, 837-851.e810. 10.1016/j.cmet.2020.03.003.

Sattler, S., Ling, G.S., Xu, D., Hussaarts, L., Romaine, A., Zhao, H., Fossati-Jimack, L., Malik, T., Cook, H.T., Botto, M., et al. (2014). IL-10-producing regulatory B cells induced by IL-33 (Breg(IL33)) effectively attenuate mucosal inflammatory responses in the gut. J Autoimmun $50,107-$ 122. 10.1016/j.jaut.2014.01.032.

Saze, Z., Schuler, P.J., Hong, C.S., Cheng, D., Jackson, E.K., and Whiteside, T.L. (2013). Adenosine production by human B cells and B cell-mediated suppression of activated T cells. Blood 122, 918. 10.1182/blood-2013-02-482406.

Singer, M., Deutschman, C.S., Seymour, C.W., Shankar-Hari, M., Annane, D., Bauer, M., Bellomo, R., Bernard, G.R., Chiche, J.D., Coopersmith, C.M., et al. (2016). The Third International Consensus Definitions for Sepsis and Septic Shock (Sepsis-3). JAMA 315, 801-810. 10.1001/jama.2016.0287.

Solomkin, J.S., Mazuski, J.E., Bradley, J.S., Rodvold, K.A., Goldstein, E.J., Baron, E.J., O'Neill, P.J., Chow, A.W., Dellinger, E.P., Eachempati, S.R., et al. (2010). Diagnosis and management of complicated intra-abdominal infection in adults and children: guidelines by the Surgical Infection Society and the Infectious Diseases Society of America. Surg Infect (Larchmt) 11, 79-109. 10.1089/sur.2009.9930.

Steinhauser, M.L., Hogaboam, C.M., Kunkel, S.L., Lukacs, N.W., Strieter, R.M., and Standiford, T.J. (1999). IL-10 is a major mediator of sepsis-induced impairment in lung antibacterial host defense. J Immunol 162, 392-399. 
1 Stuart, T., Butler, A., Hoffman, P., Hafemeister, C., Papalexi, E., Mauck, W.M., Hao, Y., Stoeckius, 2 M., Smibert, P., and Satija, R. (2019). Comprehensive Integration of Single-Cell Data. Cell 177, 3 1888-1902.e1821. 10.1016/j.cell.2019.05.031.

4 Tsui, C., Martinez-Martin, N., Gaya, M., Maldonado, P., Llorian, M., Legrave, N.M., Rossi, M., 5 MacRae, J.I., Cameron, A.J., Parker, P.J., et al. (2018). Protein Kinase C- $\beta$ Dictates B Cell Fate by 6 Regulating Mitochondrial Remodeling, Metabolic Reprogramming, and Heme Biosynthesis. 7 Immunity 48, 1144-1159.e1145. 10.1016/j.immuni.2018.04.031.

8 Tung, J.W., Mrazek, M.D., Yang, Y., and Herzenberg, L.A. (2006). Phenotypically distinct B cell 9 development pathways map to the three B cell lineages in the mouse. Proc Natl Acad Sci U S A $10103,6293-6298.10 .1073 /$ pnas.0511305103.

11 Venet, F., and Monneret, G. (2018). Advances in the understanding and treatment of sepsis12 induced immunosuppression. Nat Rev Nephrol 14, 121-137. 10.1038/nrneph.2017.165.

13 Veras, F.P., Peres, R.S., Saraiva, A.L., Pinto, L.G., Louzada-Junior, P., Cunha, T.M., Paschoal, J.A., 14 Cunha, F.Q., and Alves-Filho, J.C. (2015). Fructose 1,6-bisphosphate, a high-energy intermediate of glycolysis, attenuates experimental arthritis by activating anti-inflammatory adenosinergic pathway. Sci Rep 5, 15171. 10.1038/srep15171.

Wang, T., Derhovanessian, A., De Cruz, S., Belperio, J.A., Deng, J.C., and Hoo, G.S. (2014). Subsequent infections in survivors of sepsis: epidemiology and outcomes. J Intensive Care Med 29, 87-95. 10.1177/0885066612467162.

Waters, L.R., Ahsan, F.M., Wolf, D.M., Shirihai, O., and Teitell, M.A. (2018). Initial B Cell Activation Induces Metabolic Reprogramming and Mitochondrial Remodeling. iScience 5, 99109. 10.1016/j.isci.2018.07.005.

Yoshizaki, A., Miyagaki, T., DiLillo, D.J., Matsushita, T., Horikawa, M., Kountikov, E.I., Spolski, R., Poe, J.C., Leonard, W.J., and Tedder, T.F. (2012). Regulatory B cells control T-cell autoimmunity through IL-21-dependent cognate interactions. Nature 491, 264-268. 10.1038/nature11501.

Zamboni, D.S., Kobayashi, K.S., Kohlsdorf, T., Ogura, Y., Long, E.M., Vance, R.E., Kuida, K., Mariathasan, S., Dixit, V.M., Flavell, R.A., et al. (2006). The Birc1e cytosolic pattern-recognition receptor contributes to the detection and control of Legionella pneumophila infection. Nat Immunol 7, 318-325. 10.1038/ni1305. 